\title{
Absence of miR-378d Promoted The Malignant Phenotype of ESCC Through The AKT- $\beta$-Catenin and Hippo-p53 Signaling Pathway
}

Jie Peng

Affiliated Hospital of Jining Medical University

Juan Yu

Affiliated Hospital of Jining Medical University

Jianli Liu

Affiliated Hospital of Jining Medical University

Haixiang Wei

Affiliated Hospital of Jining Medical University

Haixia Song

Affiliated Hospital of Jining Medical University

Susu Shi

Affiliated Hospital of Jining Medical University

Shaoqiang Wang

Affiliated Hospital of Jining Medical University

Daolu Guo

Affiliated Hospital of Jining Medical University

Zhejie Li

Affiliated Hospital of Jining Medical University

Shujin He

Affiliated Hospital of Jining Medical University

Xi Feng

Affiliated Hospital of Jining Medical University

Lei Li

Affiliated Hospital of Jining Medical University

Ran Zhao

Affiliated Hospital of Jining Medical University

Yukun Liu

Affiliated Hospital of Jining Medical University

Yanrong Liu

Affiliated Hospital of Jining Medical University

Junjun Li 
Central South University

Renya Zhang

Affiliated Hospital of Jining Medical University

Wei Wang ( $\nabla$ wangwei1985@csu.edu.cn )

Afflliated Hospital of Jining Medical University https://orcid.org/0000-0002-1702-5461

Research

Keywords: miR-378d, ESCC, AKT, Hippo, polyploid tumor cells

Posted Date: December 21st, 2020

DOl: https://doi.org/10.21203/rs.3.rs-130894/v1

License: (c) (7) This work is licensed under a Creative Commons Attribution 4.0 International License. Read Full License 


\section{Abstract}

Background: Chemoresistance is an important cause of malignant progression of esophageal squamous cell carcinomas (ESCCs). miR-378d is sharply reduced in paclitaxel (PTX)-resistance esophageal cancer cells by gene-expression profile analysis (RNA-Seq), but the mechanism of miR-378d-mediated tumor progression is unclear.

Patients and methods: Herein, we detected miR-378d expression in 596 ESCC patients by in situ hybridization. Results showed that low miR-378d expression was associated with poor prognosis of ESCC patients, and that miR-378d absence enhanced carcinogenesis by promoting chemoresistance, colony formation, EMT, invasion, and metastasis.

Results: Furthermore, miR-378d can target downregulated AKT1 expression by binding to the AKT1 mRNA 3'UTR, inactivating the AKT- $\beta$-catenin signaling pathway, and reducing the epithelial-mesenchymal transition marker Vimentin and the cancer stem cell marker ALDH1A1. miR-378d silencing in ESCC cells also promoted polyploidy formation in vitro and in vivo, and miR-378d inhibition suppressed the Hippop53 signaling pathway. Consequnetly, YAP and TAZ protein accumulated in nuclei and p53 expression decreased, which may promote the formation of ploidy tumor cells.

Conclusions: Therefore, low miR-378d expression is a poor prognostic factor of ESCC patients and promotes polyploidy and cancer progression by activating AKT- $\beta$-catenin and suppressing the Hippo-p53 signaling pathway.

\section{Background}

Great progress has been made in the diagnosis and treatment of esophageal squamous cell carcinomas (ESCC) in recent years, but ESCC patients' five-year survival rate remain low and no effective targeted therapy is available ${ }^{[1]}$.. Chemotherapy, adjuvant therapy, and radiotherapy are still the main treatments for ESCC, particularly for patients in advanced stages. Acquired chemoresistance is also a frequent cause of treatment failure, and it leads to local recurrence and metastasis ${ }^{[2,3]}$.. However, the mechanism of chemoresistance of esophageal carcinoma cells and the remaining tumor cells through which postchemotherapy promotes invasion and metastasis remains unclear.

Paclitaxel (PTX), which inhibits microtubule depolymerization that leads to cell mitotic failure and tumorcell death, is a first-line chemotherapy drug for ESCCs. However, studies have shown that polyploid tumor cells (more than pentaploid) are generated after PTX treatment ${ }^{[4]}$.. Chromosomal instability (CIN) has been implicated in multidrug resistance, and polyploidy is a feature of many human cancers, so it may predispose to $\mathrm{CIN}$. Thus, the generation of aneuploidization plays a major role in carcinogenesis ${ }^{[5]}$..

Polyploidy can lead to tumorigenesis ${ }^{[6,7]}$. and promote tumor progression ${ }^{[7-9]}$.. Hippo-p53 signaling plays an important role in polyploidy, and the activation of the Hippo pathway can limit cell proliferation in at least two ways, namely, by inactivating YAP/TAZ and by stabilizing $p 53^{[6]}$.. In polyploid megakaryocytes, 
the Hippo-p53 pathway remains off as the reduction in RhoA activity fails to activate LATS1/2, allowing YAP/TAZ to translocate into the nucleus and promote target gene expression ${ }^{[10]}$.. Research has also shown that YAP activation increases hepatocyte polyploidy and synergizes with p53 inactivation to enhance liver tumorigenesis ${ }^{[6]}{ }_{\text {.. }}$

About $15.7 \%$ of AKT1 amplification is found in $\operatorname{ESCC}^{[11]}$., and a recent study has demonstrated that the $\mathrm{PI3K} / \mathrm{AKT}$ signaling pathway plays an important role in ESCC metastasis ${ }^{[12]}$.. Xanthohumol significantly inhibits AKT kinase activity in an ATP-competitive manner and decreases tumor volume and weight in patient-derived xenografts (PDXs) that highly express AKT. However, xanthohumol has no effect on PDXs that exhibit low expression of AKT in vivo ${ }^{[13]}$.. AKT promotes $\beta$-catenin stability via GSK-3 $\beta$ phosphorylation and then activates the Wnt/ $\beta$-catenin signaling pathway. Activation of the Wnt/ $\beta$-catenin signaling pathway has been implicated in epithelial-mesenchymal transition (EMT), metastasis, stemcell self-renewal, and maintenance, and differentiation of ESCC cells ${ }^{[14-18]}$..

MicroRNAs (miRNAs) play an important role in tumor chemotherapeutic resistance and tumor progression ${ }^{[19-21]}$.. In the present study, the chemoresistance of ESCC cells treated with PTX and their miRNA expression profiles were analyzed and compared with those of normal cultured cancer cells. We found that miR-378d expression was significantly downregulated in PTX-treated cells. However, the mechanism of miR-378d absence promoting chemoresistance and tumor progression in ESCC remains unclear.

\section{Methods}

\section{Cell culture}

Four human ESCC cell lines (KYSE-30, KYSE-150, KYSE-510, and TE-1) were obtained from the German Resource Center for Biological Material (DSMZ), and 293T cells were purchased from the American Type Culture Collection (USA). The ESCC cell lines were cultured in RPMI1640 (293T cells in DMEM) supplemented with 10\% fetal bovine serum (FBS; (\#04-001-1ACS, BI), 100 units/mL penicillin, and 100 $\mu \mathrm{g} / \mathrm{mL}$ streptomycin and maintained at $37^{\circ} \mathrm{C}, 5 \% \mathrm{CO}_{2}$.

\section{ESCC organization source}

A cohort of 610 subjects with ulcerative ESCCs was recruited between 2008 and 2014 from the Department of Thoracic Surgery, the Affiliated Hospital of Jining Medical University (Shandong, PR China). We collected relevant clinical data and prognostic information of patients. Among them, 470 cases were male and 140 cases were female (3.4:1), with ages ranging within 34-83 years old (mean age $=61$ years). A total of 318 patients had long-term follow-up results, and the mean survival time was 29 months (1-95.2 months).

All biopsies were immediately fixed in $4 \%$ buffered paraformaldehyde, routinely processed, and embedded with paraffin. Tumors were classified according to standard TNM staging guidelines of UICC 
(TNM Classification of Malignant Tumours, Eighth edition). The study protocol had been reviewed and approved by the local ethics committee. All patients gave written consent for their tissue samples. This research was approved by the ethics committee of Jining Medical University. Each patient signed an informed consent form.

\section{Tissue microarray}

Representative areas of the ESCC were marked on each hematoxylin-eosin (H\&E) slide and tissue paraffin block, and the marked areas of tissue paraffin blocks were sampled for TMAs. TMAs were assembled with a tissue-arraying instrument (Beecher Instruments, Silver Springs, MD, USA) as described by Kallioniemi et al. ${ }^{[22] .}$.

\section{In Situ Hybridization}

ESCC TMA was dewaxed in xylene, rehydrated in alcohol gradient, and washed two times with DEPC-PBS. The sections were treated with $2 \mu \mathrm{g} / \mathrm{mL}$ proteinase $\mathrm{K}$ (Roche) for $15 \mathrm{~min}$ at $37^{\circ} \mathrm{C}$ and washed three times with DEPC-PBS. Then, the sections were acetylated $15 \mathrm{~min}$ at room temperature (acetic anhydride in DEPC-water, $6 \mathrm{~N} \mathrm{HCl}$, and triethanolamine) and subsequently washed three times with DEPC-PBS. Sections were prehybridized in hybridization buffer ( $50 \%$ formamide; $5 \times$ saline sodium citrate; $\mathrm{pH} 7.0 ; 100$ $\mu \mathrm{g} / \mathrm{mL}$ sheared salmon sperm DNA, $0.5 \mathrm{mg} / \mathrm{mL}$ yeast tRNA, and $1 \times$ Denhardt's solution) at $58^{\circ} \mathrm{C}$ for $1 \mathrm{~h}$ before the buffer was replaced with hybridization solution containing miR probe. The miR-378d detection probes labeled with digoxin at 5'-end was from Boster (\#MK10502). Probes were diluted in prehybridization buffer to a concentration of $5 \mathrm{nM}$ and hybridized with the sections overnight at $58{ }^{\circ} \mathrm{C}$ according to the RNA melting temperature of probes. After hybridization, the sections were washed three times with $2 \times$ SSC and $0.2 \times$ SSC, permeabilized for immunostaining with $0.1 \%$ Triton X-100, and washed two times with PBS. Unspecific background was blocked with $5 \%$ swine serum diluted in PBS/BSA for 30 $\min$.

\section{PTX treatment}

All cell lines were cultured in complete medium until the cells reached $90 \%$ confluence. Different concentrations of PTX were added to the different cells, which were then treated for $24 \mathrm{~h}$. PTX was then withdrawn, the medium was replaced, and the cells were cultured until no significant cell death was observed.

\section{Sequencing of miRNA and microarray analysis}

The small RNA of TE-1 control and TE-1-PTX (9 days) treated with PTX was used for miRNA sequencing. The miRNA-sequencing libraries were constructed according to the protocol for the Illumina small RNA sample preparation kit. Sequencing was performed on an Illumina HiSeq 2000 sequencer. Library construction and sequencing were performed at Genergy Biotech (Shanghai). miRNA expression was analyzed with miRdeep2.0.0.7 [23]. and differentially expressed miRNAs were identified using an FDR 
cutoff value of 0.05 . mRNA expression profiling was conducted with Roche NimbleGen Human $12 \times 135$ K Gene Expression Array by KangChen Bio-tech. Raw data were processed with RMA algorithm, and differential expression analysis was performed with R package limma37 (Version 3.22.7).

\section{Cell transfection}

Transfection of plasmids was performed using Lipofectamine ${ }^{\mathrm{TM}} 3000$ reagent (Invitrogen, USA) according to the manufacturer's instructions. Transfection of miRNA mimics or inhibitors (Ribobio, China) was performed using Lipofectamine RNAiMAX (Invitrogen, USA) at a final concentration of $20 \mathrm{nM}$.

\section{Lentivirus packaging and transduction}

Vectors were packaged in 293FT cells using ViraPower Mix (Genepharma). After culturing for $48 \mathrm{~h}$, lentiviral particles in the supernatant were harvested and filtered by centrifugation at $500 \mathrm{~g}$ for $10 \mathrm{~min}$, and transfected into ESCC cells. The cells were then cultured under puromycin $(10 \mu \mathrm{g} / \mathrm{mL})$ selection for 2 weeks, after which real-time PCR was used to determine the level of miR-378d. Cell lines stably expressing miR-378d-inhibitor or negative control (NC) vector were designated as LV-miR-378d-inhibitor and Lv-miR-NC cells, respectively.

\section{Western Blot}

Cells were lysed in ice-cold RIPA buffer containing a protease-inhibitor cocktail (Roche). Protein content was quantified with a BCA protein assay kit (Thermo Fisher Scientific). About $30 \mu \mathrm{g}$ of protein was subjected to electrophoresis, transferred onto PVDF membranes (Millipore), and blocked with $5 \%$ nonfat dry milk in Tris-buffered saline containing $0.1 \%$ Tween 20. Membranes were incubated overnight with the following primary antibodies: anti-AKT (dilution 1:1000; CST), anti-AKT1 (1:1000; CST), anti-pAKT(Ser473) (1:1000; CST), anti-p-AKT (Thr308) (1:1000; CST), anti- $\beta$-catenin (1:2000; Proteintech), antiALDH1A1 (1:1000; Abcam), anti-Vimentin (1:500; CST), anti-MST1 (1:1000; Proteintech), anti-MST2 (1:1000; Proteintech), anti-LATS1 (1:1000; Proteintech), anti-LATS2 (1:1000; Proteintech), anti-p-LATS1/2 (1:1000; Absin), anti-YAP (1:1000; Ptoteintech), anti-p-YAP (1:1000; Absin). Anti-GAPDH antibody (1:3000; Proteintech) and anti-a-tubulin antibody (1:3000; Proteintech) served as endogenous controls. The specific bands were visualized using secondary anti-rabbit or anti-mouse antibody (1:3000; Proteintech), enhanced chemiluminescence detection kit (Millipore), and FluorChem FC2 Multi-Imager II (Alpha Innotech).

\section{Transwell migration and invasion assay}

In vitro cell migration assay was performed using transwell chambers ( $8 \mathrm{~mm}$ pore size; Corning). Cells were plated in serum-free medium ( $2 \times 10^{4}$ cells per transwell). Medium containing $15 \%$ FBS in the lower chamber served as a chemoattractant. After $48 \mathrm{~h}$, the nonmigrating cells were removed from the top face of the filters by using cotton swabs, and the migratory cells located on the bottom side of the chamber were stained with crystal violet, air dried, photographed, and counted. Images of five random fields at 10x 
magnification were captured from each membrane, and the number of migratory cells was counted. Similar inserts coated with Matrigel were used to determine the cellular invasive potential in the invasion assay.

\section{Matrigel 3D cell culture}

Cells $\left(5 \times 10^{3} / 50 \mu \mathrm{L}\right)$ were seeded onto 96 -well plates with a round-bottom lid made of ultralow attachment polystyrene (\#7007, Costar, USA). The cells were cultured overnight and found to form one sphere per well. After discarding the medium and adding $75 \mu \mathrm{L}$ of melted Matrigel (BD, USA) to resuspend the cell sphere, the mixture was incubated for $30 \mathrm{~min}$ for settling. Finally, $200 \mu \mathrm{L}$ full medium/well was added, and the medium was changed every other day.

\section{Colony-formation assays}

Cells were seeded onto six-well plates $\left(5 \times 10^{2}\right.$ cells per plate) and cultured for 10 days. The colonies were stained with $1 \%$ crystal violet for $30 \mathrm{~s}$ after fixation with $10 \%$ formaldehyde for $15 \mathrm{~min}$ and then imaged using the camera of an iPhone 5S (Apple, Inc., Cupertino, CA, USA).

\section{Dual-luciferase reporter assay}

In a typical procedure, $293 \mathrm{~T}$ cells $\left(3 \times 10^{4}\right.$ cells per well) grown on a 24 -well plate were co-transfected with luciferase reporter miRGLO-AKT1-3'UTR plasmid (WT or mutation type; Genepharma, Shanghai, China) (200 ng per well) and miR-378d (20 nM) using Lipofectamine ${ }^{\mathrm{Tm}} 3000$ (Invitrogen, USA). About $24 \mathrm{~h}$ later, a dualluciferase reporter assay kit (Promega, USA) was used to measure the luciferase and renilla activity of these samples according to the manufacturer's instructions.

\section{F-actin cytoskeleton fluorescence staining}

Cells were grown on laminin-coated glass cover slips, fixed in $4 \%$ paraformaldehyde, and stained with Phalloidin (Molecular Probes, USA). Cells were observed using a fluorescence microscope (Leica, Germany).

\section{Cell-Viability Assay}

CCK8 was used to assess cell viability. KYSE510 and TE- 1 cells $\left(1 \times 10^{4}\right)$ were seeded onto a 96-well plate in quintuplicate per well. About $12 \mathrm{~h}$ later, the cells were incubated with a gradient concentration of therapeutic drugs for $48 \mathrm{~h}$. The medium was removed, RPMI1640 $(90 \mu \mathrm{L})$ and CCK8 $(10 \mu \mathrm{L})$ were subsequently added to each well, and the mixture was incubated for $3 \mathrm{~h}$ at $37^{\circ} \mathrm{C}$. A microplate reader was used to measure the optical density (OD) at $450 \mathrm{~nm}$. The degree of drug response for tumor cells was estimated by dividing the half-maximal inhibitory concentration (IC50).

\section{Immunohistochemistry (IHC)}


IHC analysis was performed on the cell-block sections from the cultured cells by using the following primary antibodies: anti-AKT1 antibody (dilution 1:100; Proteintech), p53 (1:100, Afifinity), anti-YAP (1:100, Proteintech), anti-TAZ (1:100, Proteintech), and $\beta$-catenin (1:100, Proteintech).

\section{Immunofluorescence}

About $3 \times 10^{4}$ cells were seeded on the cover glass of sixwell plates and cultured for $48 \mathrm{~h}$. After fixing with $4 \%$ paraformaldehyde in a $37{ }^{\circ} \mathrm{C}$ water bath for 15 min to maintain cell morphology, cells were permeabilized in PBS + 0.3\% Triton X-100 for 15 min, and incubated with anti-p53 (1:100, Proteintech), anti-YAP (1:100; Affinity), and anti-TAZ (1:100; Proteintech) at $4{ }^{\circ} \mathrm{C}$ overnight, followed by anti-rabbit Cy3labeled secondary antibody (1:150; ABclonal). PBS washing was performed required for each step.

\section{Liver transplantation}

The animal protocol was approved by the ethical review committee of the Affiliated Hospital of Jining Medical University. Eight-week-old male BALB/c nude mice (Beijing Weitong Lihua Laboratory Animal Technology Co., Ltd.) were anesthetized with $4 \%$ chloraldehyde hydrate $(100 \mu \mathrm{L} / 10 \mathrm{~g})$, and body temperature was maintained by heating blankets. The thoracoabdominal skin of nude mice was sterilized with $75 \%$ alcohol and iodophor, respectively. After cutting open the skin at the lower right of the cartilago to expose the lobe of the liver, cell suspension $(50 \mu \mathrm{L} / 25 \mu \mathrm{L}$ serum-free and $25 \mu \mathrm{L}$ of Matrigel containing 500000 cells) was injected into the liver capsule slowly. Then, the syringe was pulled out and the injection port was pressed for 2-5 min with an iodophor cotton ball. Finally, the incision was sutured layer by layer according to the anatomical structure. Mice were sacrificed 44 days after tumor-cell inoculation. Afterwards, liver tissues, lung tissues, and abdominal-metastasis tumors were fixed in $4 \%$ saline-buffered formalin, embedded in paraffin, sectioned at $4 \mu \mathrm{m}$, and stained with H\&E and IHC.

\section{Statistical Analysis}

Statistical analyses were performed using the SPSS 13.0 software package (SPSS, Chicago, IL, USA) and GraphPad Prism Software (version 6, La Jolla, CA, USA). For statistical comparison of two groups, twosided Student's $t$ test with the same variances was used. Differences between variables were analyzed by two-tailed or Fisher exact tests. Survival curves were plotted using the Kaplan-Meier method and compared with log-rank tests. Multivariate survival analysis was performed for all parameters found to be significant in univariate analysis using a Cox regression model. Comparisons between groups for statistical significance were performed with a two-tailed Student $t$ test. Data are presented as the mean \pm SD. $P$ values $<0.05$ were considered significant.

\section{Results}

\section{miR-378d showed reduced expression in ESCC cells after PTX treatment}


PTX is the first-line drug for esophageal cancer, but drug resistance remains a problem. In this study, we used PTX to treat TE-1 cells. From days 2 to 9 , the cells died continuously, and only a small number of cells remained at day 9 . These cells slowly proliferated until day 20 , the remaining cells began to proliferate rapidly, and the culture bottles were covered at day 24 (Fig. 1A). The remaining PTX-treated cells at day 9 (TE-1-PTX) and DMSO-treated cells (TE-1-NC) were used to detect miRNA differential expression by sequencing. miRNA gene-expression profile data showed that miR-378d was significantly downregulated in remaining cells (Fig. 1B). In situ hybridization (ISH) assay confirmed that miR-378d was significantly downregulated in remaining PTX-treated cells, and that miR-378d was expressed in the cytoplasm and nucleus (Fig. 1C). Our data suggested that miR-378d absence may play an important role in PTX resistance.

\section{Loss of miR-378d expression corresponded to poor prognosis}

We detected miR-378d expression by ISH in a ESCC tissue array containing 610 ESCC samples because the incompleteness of the paraffin section and antigen repair led to tissue shedding. Finally, 596 specimens were obtained. The data showed that miR-378d positive staining was primarily in the cytoplasm of squamous epithelial (Fig. 2A; 208/596, 34.90\%), and miR-378d was rarely expressed in nuclei (Fig. 2B; 15/596, 2.52\%). miR-378d expression level had no clinicopathological significance with age $(p=0.269)$, gender $(p=0.864)$, tumor size $(p=0.757)$, differentiation $(p=0.249)$, stage $(p=0.305)$, LNM $(p=0.296)$, nerve invasion ( $p=0.141)$, vascular invasion $(p=0.578)$, and invasion depth $(p=0.101)$ of ESCC patients (Table 1). However, our data showed that miR-378d expression was significantly negatively associated with the overall survival rate (Fig. 2D; $p<0.0001$ ) of ESCC patients.

\section{Loss of miR-378d expression promoted chemoresistance}

Cisplatin and 5-Fu are also first-line clinical chemotherapy drugs. Our data revealed that miR-378d silencing enhanced the resistance of cisplatin at 5, 10,20,30, and $40 \mu \mathrm{M}$ for TE- 1 and KYSE-510 cells and significantly increased the LC50 of these cells (5-40 and 15-25 $\mu \mathrm{M}$, respectively) (Fig. 3a). Consistent with cisplatin treatment, miR-378d silencing also promoted 5-Fu resistance at 2.5, 5, 10, 20, $10 \mu \mathrm{g} / \mathrm{mL}$ and increased the LC50 for TE-1 (25 to $40 \mu \mathrm{g} / \mathrm{mL}$ ) and KYSE-510 (5 to $15 \mu \mathrm{g} / \mathrm{mL}$ ) (Fig. 3b), suggesting that loss of miR-378d expression played an important role in chemoresistance.

\section{Loss of miR-378d expression promoted the invasion and metastasis of ESCC}

We then detected the stress fiber formation and polymerized actin in miR-378d silencing cells and control cells using phalloidin staining. Results showed that miR-378d silencing cells underwent morphological changes, including the formation of an obvious actin filament cytoskeleton and an expansive morphological structure compared with control TE- 1 and KYSE-510 cells (Fig. 4a). In vitro invasion assays using Matrigel-coated membranes revealed that the invasive potential of miR-378d cells was reduced compared with that of controls (Fig. $4 \mathrm{~b} ; P<0.001$ ). Results of migration assay with Matrigelcoated free membranes were consistent with those of the invasion assays (Fig. $4 \mathrm{~b} ; P<0.001$ ). These findings suggested that miR-378d inhibited EMT. Colony-formation assay further showed that miR-378d 
silencing significantly enhanced the monoclonal colony-formation ability in TE- 1 and KYSE-510 cells (Fig. 4c; $P=0.0004$ and $P=0.0003$ ). Tumor-sphere-formation assay showed that 5000 ESCC cells aggregated into sphere culture overnight for ESCC cells, and that loss of miR-378d expression induced cell shedding from spheres at day 4 (Fig. 4d). We also found that miR-378d lost expression promoted the invasion of sphere in Matrigel (Fig. 4e).

Liver is a common metastasis site of esophageal cancer, so liver-transplantation assay was performed to analyze the metastatic ability of tumor cells without miR-378d expression. KYSE-150-miR-NC and KYSE150-miR-378d-inhibitor cells were transplanted into subcapsular liver of BALB/c nude mice (hereafter denoted as NC-mice and In-mice, respectively. The experiment was terminated after 44 days. The body weight of In-mice was significantly lower than that of NC-mice at day $44(P=0.011$, Fig.s $4 \mathrm{f} \mathrm{\&} \mathrm{g)}$. Before the end of the experiment, NC-mice did not die (0/6), but two IN-mice (2/6) died at days 35 and 38, respectively (Fig. 4h). Although the number of liver nodules in In-mice was more than that in NC-mice, no statistical difference (Fig.s $4 \mathrm{i} \& \mathrm{k}$ ) was observed. Tumor cells basically metastasized to the abdominal cavity, and no metastasis was found in all lung tissues. Abdominal metastatic tumors appeared in $5 / 6$ of the NC-mice and $6 / 6$ of the In-mice (Fig. 4j). The number of abdominal-metastasis tumors in In-mice was more than that in NC-mice (Fig. $4 \mathrm{I}, P=0.026$ ), and the volume was also larger than that of the NC-mice. These data showed that loss of miR-378d expression promoted tumor metastasis.

\section{miR-378d regulated the AKT- $\beta$-catenin pathway in ESCC}

The pathway-enrichment statistical scatterplot showed that TE-1 NC and TE-1-PTX differential miRNA target molecules were enriched in the PI3K-AKT signaling pathways (Fig. 5a). Differential mRNA expression analysis showed that in TE-1-PTX cells, 29 mRNA significantly increased and 18 mRNA were significant decreased. These molecules were closely related to the AKT signaling pathway. Gene-set enrichment analysis (GSEA) data also showed that differentially expressed genes of TE-1-PTX were enriched for AKT (Fig. 5b). The miRTarBase online software (http://mirtarbase.mbc.nctu.edu.tw/php/index.php) predicted that AKT1 was a potential target gene of miR-378d (Fig. 5c). Dual-luciferase activity assay revealed that miR-378d targeted the 3'UTR of AKT1 mRNA (Fig. 5d). Transient transfection of miR-378d mimics to TE-1 cells decreased the AKT1 and p-AKT (T308 and S473) protein expression levels (Fig. 4e). Stable transfection of miR-378d inhibitor to TE-1 and KYSE-510 cells increased the total AKT1 and p-AKT (T308 and S473) expression (Fig. 5f). The IHC assay data also showed that miR-378d inhibition increased the protein expression levels of AKT1 in vitro of cells (TE-1) and xenografted tumors (KYSE-150) (Fig.s 4k \& I). These data indicated that miR-378d target regulated AKT1. GSEA data further revealed that differentially expressed genes of TE-1-PTX were enriched for CTNNB1 ( $\beta$-catenin) oncogenic signature, which was the AKT regulated pathway (Fig. $5 \mathrm{~g}$ ). The protein expression levels of $\beta$-catenin and the downstream target genes vimentin and ALDH1A1 decreased in cells with highly expressed miR-378d (Fig. 5h), whereas absent miR-378d expression increased these levels (Fig. 4i). The data showed that miR-378d absence activated the $\beta$-catenin pathway. 
To determine whether miR-378d regulated the downstream genes' ( $\beta$-catenin, vimentin, and ALDH1A1) expression by targeting AKT1, we treated TE-1 cells with inhibitors to suppress AKT expression. AKT inhibitor MK-2206 downregulated the protein expression levels of AKT1, p-AKT, and the downstream $\beta$ catenin and ALDH1A1 in TE-1-miR-378d-inhibitor cells (Fig. 5I), suggesting that miR-378d silencing activated the AKT- $\beta$-catenin signaling pathway. Our data also showed that inhibiting $\beta$-catenin in turn inhibited AKT1 expression (Fig. 5l); thus, AKT and $\beta$-catenin formed a positive feedback loop.

\section{Loss of miR-378d expression promoted polyploidy}

We found that remaining PTX-treated cells were mostly large cells (Fig. 1a, day 9; Fig.s 1c \& 6a, day 9). The polyploid cells $(\geq 5 \mathrm{~N})$ significantly increased after PTX treatment (Fig. 6a). Circulating tumor cells (CTCs) are closely related to tumor metastasis ${ }^{[24]}$. and were usually defined as tumor ploidy $\geq 3 \mathrm{~N}$. In the blood of ESCCs, we detected the CTCs of different ploidy cells (2N, $3 \mathrm{~N}, 4 \mathrm{~N}$, and $\geq 5 \mathrm{~N})$ (Fig. 6b). We also analyzed the ploidy cells' proportion in ESCC and found that $3 \mathrm{~N}$ was the most abundant (68.5\%), followed by $4 \mathrm{~N}(25.6 \%)$ and $\geq 5 \mathrm{~N}(5.9 \%)$ (Fig. $6 \mathrm{c}), 2 \mathrm{~N}$ tumor cells were rare and hard to distinguish from leucocytes in ESCC CTCs. DNA ploidy analysis showed that miR-378d silencing promoted polyploidtumor-cell formation in TE-1 and KYSE-150 cells (Fig. 6d). Then, we detected polyploid-tumor-cell formation after PTX treatment, and data showed that miR-378d silencing promoted cell survival and increased the number of polyploid tumor cells in TE-1 and KYSE-150 cells (Fig. 6e, $P<0.001$ ) in vitro. Liver-transplantation tumor was used to detect the formation of polyploid tumor cells in vivo, and KYSE150-NC and KYSE-150-miR-378d-in cells were transferred sequentially. Polyploid tumor cells dramatically increased in liver-transplantation tumor and abdominal-metastasis tumor in the miR-378d silencing group (Fig. 6f). FISH data confirmed that the large cells were polyploid tumor cells (Fig. 6h). These findings showed that loss of miR-378d promoted polyploid-tumor-cell formation in vitro and in vivo.

\section{miR-378d regulated Hippo-p53 signaling}

The downregulation of miR-378d promoted polyploid production in vitro and in vivo. The Hippo-p53 signaling pathway is well known to regulate polyploidy formation, and our GSEA data showed that differentially expressed genes of TE-1 polyploid tumor cells were enriched in the YAP1 and P53 pathway (Fig. 7a). Then, we detected the Hippo-p53 signaling-protein expression levels, and Western blotting data revealed that the transient overexpression of miR-378d mimics increased the expression of p-LATS1/2, p53, and p-YAP. Conversely, the total YAP and TAZ protein expression levels decreased in KYSE510 cells (Fig. 7b), and lost miR-378d expression inhibited the expression of MST1, p-LATS1/2, p53 and p-YAP, thereby increasing the total YAP and TAZ protein expression levels in TE-1 and KYSE510 cells (Fig. 7c). We also detected the expression of YAP1 and P53 in the cytoplasm and nucleus by Western blotting, and results revealed that YAP1 protein was primarily expressed in the cytoplasm. Moreover, YAP1 protein nuclear translocation increased in KYSE-510 and KYSE-150 cells, and P53 protein nuclear translocation decreased in KYSE-510,TE-1 and KYSE-150 cells (Fig. 7d). Immunofluorescence data indicated that miR378d absence reduced the TP53 expression and increased the YAP1 and TAZ expression of TE-1 cells in vitro (Fig. 7e). In abdominal-metastasis tumors, loss of miR-378d expression also reduced TP53 
expression and increased YAP1 and TAZ expression in In-mice (Fig. 7f, KYSE-150 cells). This finding suggested that lost miR-378d expression inactivated the Hippo-TP53 signaling pathway and activated YAP/TAZ, thereby playing an important role in polyploidy formation in ESCCs.

\section{Discussion}

miR-378d is a member of the miR-378 family, which includes 10 members, namely, miR-378a, b, c, d, e, f, $\mathrm{g}, \mathrm{h}, \mathrm{i}$, and j. Most research has primarily focused on miR-378a and miR-378b ${ }^{[25]}$, and only a few studies have been performed on miR-378d and inflammation ${ }^{[26]}$. or infection ${ }^{[27]}$. In the current work, miR-378d significantly decreased in PTX-treatment surviving cells; however, the role of miR-378d in tumor remains unclear. Our data showed that miR-378d inhibited AKT1 expression by target binding the 3'UTR of AKT1 mRNA and inactivating AKT signaling. AKT signaling pathway is closely related to multidrug resistance, such as PTX ${ }^{[28]}$, cisplatin ${ }^{[29]}$, 5-Fu ${ }^{[30]}$, temozolomide ${ }^{[31]}$, tamoxifen ${ }^{[32]}$, MEK inhibitor ${ }^{[33]}$, melphalan ${ }^{[34]}$, etc. Survival data also demonstrated that miR-378d inhibition promoted cisplatin and 5-Fu resistance.

AKT- $\beta$-catenin signaling plays an important role in promoting tumor EMT ${ }^{[35]}$. and metastasis ${ }^{[36,37]}$. We have previously reported that AKT- $\beta$-catenin-ALDH1A1 can form a positive feedback regulatory loop to promote the characteristics of cancer stem cells (CSCs) ${ }^{[38,39]}$. In the present study, we reported that miR$378 \mathrm{~d}$ suppressed the AKT- $\beta$-catenin circuit loop. AKT and $\beta$-catenin also positively regulated each other, as well as the CSC marker ALDH1A1 and the mesenchymal cell marker Vimentin. Furthermore, miR-378d absence promoted EMT and metastasis in vitro and in vivo.

Tumors, even cell lines cultured in vitro, are complex systems that include heterogeneous cancer cells with markedly different sizes and genomic contents ${ }^{[40]}$. These cells include bulk, stem, and polyploidy cells. The bulk of cancer cells within the majority are aneuploid. CSCs are often much smaller than bulk cells, whereas polyploid cells are larger owing to their increased ploidy $(>4 n)^{[41]}$. CD133 has been suggested as a broad-spectrum marker for CSCs. CD $133^{+}$cells are small, regular, and round with small microvilli. In some fields, several giant cancer cells the $\mathrm{CD}_{133^{+}}$cell group have been identified under a light microscope, and most of them are found to be polynuclear in NPC cells ${ }^{[42]}$. Studies have shown that polyploidy tumor cells express tumor-stem-cell markers. Li Zhang et al. [8]. detected the upregulation of EZH2 expression in polyploid tumor cells and found that a histone lysine N-methyltransferase plays a key role in embryogenesis and CSCs. The expression of ALDH1 was higher in HEY-Polyploid tumor cells than in normal cancer cells, and CD133 and CD117 were expressed in HEY-Polyploid tumor cells but not in normal cancer cells ${ }^{[43]}$. Their conclusion is the same as that drawn from a study on PTX-treated breast cancer cell line MCF-7 ${ }^{[44]}$, which showed that polyploidy tumor cells are a subgroup of CSCs in normal cancer cells and PTX-treated cells. Other researchers have revealed that polyploid giant cancer cells produce daughter cells with CSC characteristics through budding ${ }^{[43,45]}$. Polyploidy tumor cells produce small daughter cells by budding, which may be also be CSCs. Daughter cells are produced by polyploidy tumor cells, which may lead to tumor heterogeneity by differentiation. 
In the present study, we identified a critical role for miR-378d during cancer-cell polyploidy and in malignant tumor phenotypes. miR-378d expression inhibition increased cancer-cell polyploidy in vitro and in vivo. Cancer-cell polyploidy is important for tumorigenesis and progression, but how polyploid-tumor cells form remain largely unknown. JNK and Yorkie are co-activated to form polyploid tumor cells through endogenous replication, i.e., Yorkie upregulates Diap1 phenotype of and Diap1 and JNK downregulates cyclin B (Cyc B) in G2/M cells, thereby inducing intracellular replication ${ }^{[46]}$. Interestingly, malignant tumors induced by RAS activation and cell-polarity defects also comprise polyploid tumor cells, which are also caused by JNK and Yorkie mediated CycB downregulation. Polyploid tumor cells can be eliminated from this malignant tumor though blocking endogenous replication, which strongly inhibits the growth and metastasis of tumors ${ }^{[46]}$. Endoduplication cell cycle plays an important role in the development of plants, Drosophila melanogaster, and several mammalian cells and organs including megakaryocytes, hepatocytes, and placentas ${ }^{[47]}$. RhoA and AKT play important roles in F-actin skeleton rearrangement ${ }^{[48,}$ 49]. Cytokinesis failure in erythroblasts has been reported in a mouse model with erythroid-specific deletion of RhoA ${ }^{[50]}$.

We found that polyploid-tumor-cell formation by PTX treatment was similar to megakaryocyte formation. During endomitosis, megakaryocytes proceed through successive cell cycles without cell division to reach DNA contents of $32 \mathrm{~N}, 64 \mathrm{~N}$, and even $128 \mathrm{~N}$. After completion of the $\mathrm{G} 1, \mathrm{~S}$, and $\mathrm{G} 2$ phases, committed megakaryocytes enter mitosis, transition through anaphase, separate their chromosomes, and initiate cleavage-furrow formation ${ }^{[51]}$. Polyploid tumor cells treated with PTX undergo endomitosis and separated their chromosomes to their daughter cells through pseudopodia or budding, as in the asymmetric cell-division model ${ }^{[47,52,53]}$. In diploid cells, increasing the phosphorylation of LATS1/2 inhibits the transcriptional coactivators YAP and TAZ. In parallel, LATS1/2 stabilizes p53 by disrupting the MDM2-p53 interaction. In polyploid megakaryocytes, the Hippo-p53 pathway remains off as the reduction in RhoA activity fails to activate LATS1/2, allowing YAP/TAZ to translocate into the nucleus and promoting target gene expression ${ }^{[10]}$. In the present study, miR-378d inhibition promoted polyploidy in vitro and in vivo, suppressed LATS1/2, p-YAP, and p53 expression, and promoted TAZ protein expression. Moreover, the presence of extra centrosomes and actin filaments, a consequence of the increased number of chromosomes, was found to activate the Hippo-p53 pathway by downregulating RhoA activity ${ }^{[54]}$. Thus, miR-378d lost expression promotes polyploid cancer cells formed by inactivating the Hippo-p53 signaling pathway and increasing YAP/TAZ nucleus translocation.

PTX stabilizes microtubule polymers, blocking cell cycle in G2-M phase and hindering the development of

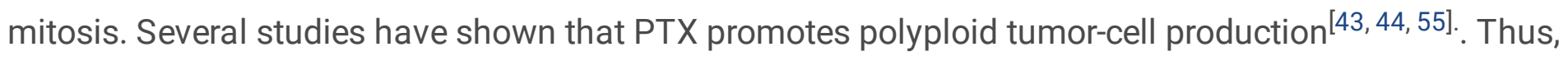
considering that polyploid tumor cells promoted chemoresistance and cancer progression, the clinical application of PTX should be re-evaluated or the combination therapy for targeting polyploid should be developed.

\section{Conclusions}


We reported for the first time that low miR-378d expression was associated with poor prognosis in ESCC patients. Low miR-378d expression can suppress Hippo-p53 and promote the AKT- $\beta$-catenin signaling pathway, thereby also promoting polyploidy and cancer progression.

\section{Abbreviations}

Esophageal carcinoma (EC); ESCC: esophageal squamous cell carcinoma; PCCs: polyploid cancer cells; EGFR: epidermal growth factor receptor; AKT: protein kinase B; YAP: Yes associated protein; RhoA: ras homolog family member A; p53: tumor protein p53; TAZ: tafazzin; LATS: large tumor suppressor kinase 1; Skp2: S-phase kinase associated protein 2; FoxO: forkhead box 0; PI3K: phosphatidylinositol 3-kinase;

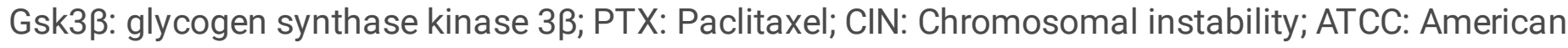
Type Culture Collection; CD133: prominin 1; CD44 : CD44 molecule (Indian blood group); ALDH1A1: aldehyde dehydrogenase 1; c-Myc: MYC proto-oncogene, bHLH transcription factor ; GAPDH: glyceraldehyde-3-phosphate dehydrogenase; TMA: Tissue microarray; PDXs: patient-derived xenografts; FBS: fetal bovine serum; epithelial-mesenchymal transition (EMT); qRT-PCR: Quantitative reverse transcription-polymerase chain reaction; RNA-Seq: RNA sequencing; H\&E: hematoxylin-eosin staining;

\section{Declarations}

\section{Acknowledgement}

We thank Dr. Bo Xiang and Zhibin Yu for their kind help on the initiation of this research.

\section{Author contributions}

WW designed the study. LL, RZ, RZ, YL, and YL oversaw the study. HW, HS, XF, and SW provided clinical samples. JP, YY, ZL, SS, JL, and DG performed the majority of the experiments and analyzed the data. JP, $J L$, and $\mathrm{SH}$ performed a number of the animal experiments. LL provided research assistance. RZ, YL, YL, and $\mathrm{RZ}$ reviewed and edited the article. WW takes responsibility for the accuracy of the data analysis. WW wrote the article.

\section{Funding}

This research was supported by The National Natural Science Foundation of China (81802945), Jining Science and Technology Key Research and Development Plan (2018SMNS006), The PhD Research Foundation Affiliated Hospital of Jining Medical University (2016-BS-002); The cultivation project of the National Natural Science Foundation of Jining Medical University (JYP201733, JYP201731); Research support found for young teachers of Jining Medical University (JY2017FS007, JYP201731, JYFC2019FKJ048, JYFC2019FKJ037, JYFC2019FKJ165). Youth Innovation and technology support program in Shandong Province (2020KJL003).

\section{Availability of data and materials}


Datasets used and/or analyzed during the current study are available from the corresponding author on reasonable request.

\section{Ethics approval and consent to participate}

The present study was approved by the Medical Ethics Committee of Affiliated Hospital of Jining Medical University and Experimental animal ethics committee of Jining Medical University.

\section{Consent for publication}

Not applicable.

\section{Competing interests}

The authors declare that they have no competing interests.

\section{Author details}

1. Department of Pathology, Affiliated Hospital of Jining Medical University, Jining Medical University, Jining, Shandong 272029, China

2. Department of Pathology, Zibo Central Hospital, Zibo, Shandong 255036, China.

3. Department of Pathology, The First People's Hospital of Xuzhou, Xuzhou, Jiangsu 221106, China

4. Department of Thoracic Surgery, Affiliated Hospital of Jining Medical University, Jining Medical University, Jining, Shandong 272029, China

5. Cancer Research Institute and School of Basic Medical Sciences, Central South University, Changsha, Hunan 410078, China

\section{References}

1. Xiong JX, Wang YS, Sheng J, Xiang D, Huang TX, Tan BB, Zeng CM, Li HH, Yang J, Meltzer SJ, et al. Epigenetic alterations of a novel antioxidant gene SLC22A3 predispose susceptible individuals to increased risk of esophageal cancer. Int J Biol Sci. 2018; 14: 1658-1668.

2. Abbas G,Krasna M. Overview of esophageal cancer. Ann Cardiothorac Surg. 2017; 6: 131-136.

3. Tomasello G, Ghidini M, Barni S, Passalacqua R, Petrelli F. Overview of different available chemotherapy regimens combined with radiotherapy for the neoadjuvant and definitive treatment of esophageal cancer. Expert Rev Clin Pharmacol. 2017; 10: 649-660.

4. Li JC, Liu D, Yang Y, Wang XY, Pan DL, Qiu ZD, Su Y, Pan JJ. Growth, clonability, and radiation resistance of esophageal carcinoma-derived stem-like cells. Asian Pac J Cancer Prev. 2013; 14: 48916.

5. Tormos AM, Talens-Visconti R, Sastre J. Regulation of cytokinesis and its clinical significance. Crit Rev Clin Lab Sci. 2015; 52: 159-67. 
6. Zhang S, Chen Q, Liu Q, Li Y, Sun X, Hong L, Ji S, Liu C, Geng J, Zhang W, et al. Hippo Signaling Suppresses Cell Ploidy and Tumorigenesis through Skp2. Cancer Cell. 2017; 31: 669-684.

7. Zhang S, Mercado-Uribe I, Xing Z, Sun B, Kuang J, Liu J. Generation of cancer stem-like cells through the formation of polyploid giant cancer cells. Oncogene. 2014; 33: 116-28.

8. Zhang L, Ding P, Lv H, Zhang D, Liu G, Yang Z, Li Y, Liu J, Zhang S. Number of polyploid giant cancer cells and expression of EZH2 are associated with VM formation and tumor grade in human ovarian tumor. Biomed Res Int. 2014; 2014: 903542.

9. Lopez-Sanchez LM, Jimenez C, Valverde A, Hernandez V, Penarando J, Martinez A, Lopez-Pedrera C, Munoz-Castaneda JR, De la Haba-Rodriguez JR, Aranda E, et al. CoCl2, a mimic of hypoxia, induces formation of polyploid giant cells with stem characteristics in colon cancer. PLoS One. 2014; 9: e99143.

10. Suraneni PK,Crispino JD. The Hippo-p53 pathway in megakaryopoiesis. Haematologica. 2016; 101: 1446-1448.

11. Song Y, Li L, Ou Y, Gao Z, Li E, Li X, Zhang W, Wang J, Xu L, Zhou Y, et al. Identification of genomic alterations in oesophageal squamous cell cancer. Nature. 2014; 509: 91-5.

12. Li B, Xu WW, Lam AKY, Wang Y, Hu HF, Guan XY, Qin YR, Saremi N, Tsao SW, He QY, et al. Significance of PI3K/AKT signaling pathway in metastasis of esophageal squamous cell carcinoma and its potential as a target for anti-metastasis therapy. Oncotarget. 2017; 8: 38755-38766.

13. Liu X, Song M, Wang P, Zhao R, Chen H, Zhang M, Shi Y, Liu K, Liu F, Yang R, et al. Targeted therapy of the AKT kinase inhibits esophageal squamous cell carcinoma growth in vitro and in vivo. Int $J$ Cancer. 2019;

14. Espada J, Calvo MB, Diaz-Prado S, Medina V. Wnt signalling and cancer stem cells. Clin Transl Oncol. 2009; 11: 411-27.

15. Ge C, Wu S, Wang W, Liu Z, Zhang J, Wang Z, Li R, Zhang Z, Li Z, Dong S, et al. miR-942 promotes cancer stem cell-like traits in esophageal squamous cell carcinoma through activation of Wnt/betacatenin signalling pathway. Oncotarget. 2015; 6: 10964-77.

16. Zhong YB, Shan AJ, Lv W, Wang J, Xu JZ. Long non-coding RNA LINC00675 inhibits tumorigenesis and EMT via repressing Wnt/beta-catenin signaling in esophageal squamous cell carcinoma. Eur Rev Med Pharmacol Sci. 2018; 22: 8288-8297.

17. Zhao YL, Li JB, Li YJ, Li SJ, Zhou SH, Xia H. Capn4 promotes esophageal squamous cell carcinoma metastasis by regulating ZEB1 through the Wnt/beta-catenin signaling pathway. Thorac Cancer. 2019; 10: 24-32.

18. Lee KB, Ye S, Park MH, Park BH, Lee JS, Kim SM. p63-Mediated activation of the beta-catenin/c-Myc signaling pathway stimulates esophageal squamous carcinoma cell invasion and metastasis. Cancer Lett. 2014; 353: 124-32.

19. Geretto M, Pulliero A, Rosano C, Zhabayeva D, Bersimbaev R, Izzotti A. Resistance to cancer chemotherapeutic drugs is determined by pivotal microRNA regulators. Am J Cancer Res. 2017; 7: 1350-1371. 
20. Thyagarajan A, Tsai KY, Sahu RP. MicroRNA heterogeneity in melanoma progression. Semin Cancer Biol. 2019; 59: 208-220.

21. Lee K,Ferguson LR. MicroRNA biomarkers predicting risk, initiation and progression of colorectal cancer. World J Gastroenterol. 2016; 22: 7389-401.

22. Kallioniemi OP, Wagner U, Kononen J, Sauter G. Tissue microarray technology for high-throughput molecular profiling of cancer. Hum Mol Genet. 2001; 10: 657-62.

23. Friedlander MR, Chen W, Adamidi C, Maaskola J, Einspanier R, Knespel S, Rajewsky N. Discovering microRNAs from deep sequencing data using miRDeep. Nat Biotechnol. 2008; 26: 407-15.

24. Gkountela S, Castro-Giner F, Szczerba BM, Vetter M, Landin J, Scherrer R, Krol I, Scheidmann MC, Beisel C, Stirnimann CU, et al. Circulating Tumor Cell Clustering Shapes DNA Methylation to Enable Metastasis Seeding. Cell. 2019; 176: 98-112.

25. Krist B, Florczyk U, Pietraszek-Gremplewicz K, Jozkowicz A, Dulak J. The Role of miR-378a in Metabolism, Angiogenesis, and Muscle Biology. Int J Endocrinol. 2015; 2015: 281756.

26. Valmiki S, Ahuja V, Paul J. MicroRNA exhibit altered expression in the inflamed colonic mucosa of ulcerative colitis patients. World J Gastroenterol. 2017; 23: 5324-5332.

27. Zhu Y, Xiao Y, Kong D, Liu H, Chen X, Chen Y, Zhu T, Peng Y, Zhai W, Hu C, et al. Down-Regulation of miR-378d Increased Rab10 Expression to Help Clearance of Mycobacterium tuberculosis in Macrophages. Front Cell Infect Microbiol. 2020; 10: 108.

28. Liu L, Meng T, Zheng X, Liu Y, Hao R, Yan Y, Chen S, You H, Xing J, Dong Y. Transgelin 2 Promotes Paclitaxel Resistance, Migration, and Invasion of Breast Cancer by Directly Interacting with PTEN and Activating PI3K/Akt/GSK-3beta Pathway. Mol Cancer Ther. 2019; 18: 2457-2468.

29. Zhang C, He LJ, Zhu YB, Fan QZ, Miao DD, Zhang SP, Zhao WY, Liu XP. Piperlongumine Inhibits Akt Phosphorylation to Reverse Resistance to Cisplatin in Human Non-Small Cell Lung Cancer Cells via ROS Regulation. Front Pharmacol. 2019; 10: 1178.

30. Kim EJ, Kang GJ, Kang JI, Boo HJ, Hyun JW, Koh YS, Chang WY, Kim YR, Kwon JM, Maeng YH, et al. Over-activation of AKT signaling leading to 5-Fluorouracil resistance in SNU-C5/5-FU cells. Oncotarget. 2018; 9: 19911-19928.

31. Dai S, Yan Y, Xu Z, Zeng S, Qian L, Huo L, Li X, Sun L, Gong Z. SCD1 Confers Temozolomide Resistance to Human Glioma Cells via the Akt/GSK3beta/beta-Catenin Signaling Axis. Front Pharmacol. 2017; 8: 960.

32. Li D, Ji H, Niu X, Yin L, Wang Y, Gu Y, Wang J, Zhou X, Zhang H, Zhang Q. Tumor-associated macrophages secrete $\mathrm{CC}$-chemokine ligand 2 and induce tamoxifen resistance by activating $\mathrm{PI3K} / \mathrm{Akt} / \mathrm{mTOR}$ in breast cancer. Cancer Sci. 2020; 111: 47-58.

33. Tsubaki M, Takeda T, Noguchi M, Jinushi M, Seki S, Morii Y, Shimomura K, Imano M, Satou T, Nishida S. Overactivation of Akt Contributes to MEK Inhibitor Primary and Acquired Resistance in Colorectal Cancer Cells. Cancers (Basel). 2019; 11:

34. Tsubaki M, Takeda T, Tomonari Y, Koumoto YI, Imano M, Satou T, Nishida S. Overexpression of HIF1alpha contributes to melphalan resistance in multiple myeloma cells by activation of ERK1/2, Akt, 
and NF-kappaB. Lab Invest. 2019; 99: 72-84.

35. McCubrey JA, Fitzgerald TL, Yang LV, Lertpiriyapong K, Steelman LS, Abrams SL, Montalto G, Cervello M, Neri LM, Cocco L, et al. Roles of GSK-3 and microRNAs on epithelial mesenchymal transition and cancer stem cells. Oncotarget. 2017; 8: 14221-14250.

36. Wang C, Ruan P, Zhao Y, Li X, Wang J, Wu X, Liu T, Wang S, Hou J, Li W, et al. Spermidine/spermine $\mathrm{N} 1$-acetyltransferase regulates cell growth and metastasis via AKT/beta-catenin signaling pathways in hepatocellular and colorectal carcinoma cells. Oncotarget. 2017; 8: 1092-1109.

37. Zhou K, Chen J, Wu J, Xu Y, Wu Q, Yue J, Song Y, Li S, Zhou P, Tu W, et al. Profilin 2 Promotes Proliferation and Metastasis of Head and Neck Cancer Cells by Regulating PI3K/AKT/beta-Catenin Signaling Pathway. Oncol Res. 2019; 27: 1079-1088.

38. Wang W, Yi M, Chen S, Li J, Zhang H, Xiong W, Li G, Li X, Xiang B. NOR1 Suppresses Cancer StemLike Cells Properties of Tumor Cells via the Inhibition of the AKT-GSK-3beta-Wnt/beta-cateninALDH1A1 Signal Circuit. J Cell Physiol. 2017; 232: 2829-2840.

39. Wang W, He S, Zhang R, Peng J, Guo D, Zhang J, Xiang B, Li L. ALDH1A1 maintains the cancer stemlike cells properties of esophageal squamous cell carcinoma by activating the AKT signal pathway and interacting with beta-catenin. Biomed Pharmacother. 2020; 125: 109940.

40. Li Q, Rycaj K, Chen X, Tang DG. Cancer stem cells and cell size: A causal link? Semin Cancer Biol. 2015; 35: 191-9.

41. Mirzayans R, Andrais B, Murray D. Roles of Polyploid/Multinucleated Giant Cancer Cells in Metastasis and Disease Relapse Following Anticancer Treatment. Cancers (Basel). 2018; 10 :

42. Jiang Q, Zhang Q, Wang S, Xie S, Fang W, Liu Z, Liu J, Yao K. A Fraction of CD133+ CNE2 Cells Is Made of Giant Cancer Cells with Morphological Evidence of Asymmetric Mitosis. J Cancer. 2015; 6: 1236-44.

43. Niu N, Mercado-Uribe I, Liu J. Dedifferentiation into blastomere-like cancer stem cells via formation of polyploid giant cancer cells. Oncogene. 2017; 36: 4887-4900.

44. Zhang S, Mercado-Uribe I, Liu J. Tumor stroma and differentiated cancer cells can be originated directly from polyploid giant cancer cells induced by paclitaxel. Int J Cancer. 2014; 134: 508-18.

45. Zhang S, Mercado-Uribe I, Hanash S, Liu J. iTRAQ-based proteomic analysis of polyploid giant cancer cells and budding progeny cells reveals several distinct pathways for ovarian cancer development. PLoS One. 2013; 8: e80120.

46. Cong B, Ohsawa S, Igaki T. JNK and Yorkie drive tumor progression by generating polyploid giant cells in Drosophila. Oncogene. 2018; 37: 3088-3097.

47. Niu N, Zhang J, Zhang N, Mercado-Uribe I, Tao F, Han Z, Pathak S, Multani AS, Kuang J, Yao J, et al. Linking genomic reorganization to tumor initiation via the giant cell cycle. Oncogenesis. 2016; 5: e281.

48. Hsu CR, Pan YJ, Liu JY, Chen CT, Lin TL, Wang JT. Klebsiella pneumoniae translocates across the intestinal epithelium via Rho GTPase- and phosphatidylinositol 3-kinase/Akt-dependent cell invasion. Infect Immun. 2015; 83: 769-79.

Page $18 / 29$ 
49. Cuartas-Lopez AM, Hernandez-Cuellar CE, Gallego-Gomez JC. Disentangling the role of PI3K/Akt, Rho GTPase and the actin cytoskeleton on dengue virus infection. Virus Res. 2018; 256: 153-165.

50. Konstantinidis DG, Giger KM, Risinger M, Pushkaran S, Zhou P, Dexheimer P, Yerneni S, Andreassen P, Klingmuller $\mathrm{U}$, Palis $\mathrm{J}$, et al. Cytokinesis failure in RhoA-deficient mouse erythroblasts involves actomyosin and midbody dysregulation and triggers p53 activation. Blood. 2015; 126: 1473-82.

51. Vitrat N, Cohen-Solal K, Pique C, Le Couedic JP, Norol F, Larsen AK, Katz A, Vainchenker W, Debili N. Endomitosis of human megakaryocytes are due to abortive mitosis. Blood. 1998; 91: 3711-23.

52. Zhang S, Zhang D, Yang Z, Zhang X. Tumor Budding, Micropapillary Pattern, and Polyploidy Giant Cancer Cells in Colorectal Cancer: Current Status and Future Prospects. Stem Cells Int. 2016; 2016: 4810734.

53. Lv H, Shi Y, Zhang L, Zhang D, Liu G, Yang Z, Li Y, Fei F, Zhang S. Polyploid giant cancer cells with budding and the expression of cyclin E, S-phase kinase-associated protein 2, stathmin associated with the grading and metastasis in serous ovarian tumor. BMC Cancer. 2014; 14: 576.

54. Ganem NJ, Cornils H, Chiu SY, O'Rourke KP, Arnaud J, Yimlamai D, Thery M, Camargo FD, Pellman D. Cytokinesis failure triggers hippo tumor suppressor pathway activation. Cell. 2014; 158: 833-848.

55. Chen J, Niu N, Zhang J, Qi L, Shen W, Donkena KV, Feng Z, Liu J. Polyploid Giant Cancer Cells (PGCCs): The Evil Roots of Cancer. Curr Cancer Drug Targets. 2019; 19: 360-367.

\section{Tables}

Table1. miR-378d expression in ESCC patients and its clinicpathological significance, 596 case 


\begin{tabular}{|c|c|c|c|c|c|}
\hline \multirow[t]{2}{*}{ Clinical information } & miR-378d & miR-378d ${ }^{\text {High }}$ & \multirow[t]{2}{*}{ total } & \multirow[t]{2}{*}{ c2 } & \multirow[t]{2}{*}{$P$} \\
\hline & $\mathrm{N}(\%)$ & $\mathrm{N}(\%)$ & & & \\
\hline \multicolumn{6}{|l|}{ Age(years) } \\
\hline$\geq 61$ & 198(63.06) & 116(36.94) & 314 & 1.220 & 0.269 \\
\hline$<61$ & $190(67.38)$ & $92(32.62)$ & 282 & & \\
\hline \multicolumn{6}{|l|}{ Gender } \\
\hline Male & $299(65.28)$ & 159(34.72) & 458 & 0.029 & 0.864 \\
\hline Female & $89(64.49)$ & $49(35.08)$ & 138 & & \\
\hline \multicolumn{6}{|l|}{ Tumor size(cm) } \\
\hline$>4$ & $143(65.90)$ & $74(34.10)$ & 217 & 0.096 & 0.757 \\
\hline$\leq 4$ & $245(64.64)$ & 134(35.36) & 379 & & \\
\hline \multicolumn{6}{|l|}{ Stage } \\
\hline$\nabla+\nabla$ & $112(68.29)$ & $52(31.71)$ & 164 & 1.052 & 0.305 \\
\hline$\nabla+\rrbracket$ & $275(63.81)$ & 156(36.19) & 431 & & \\
\hline \multicolumn{6}{|l|}{ LNM } \\
\hline Negative & 199(63.17) & 116(36.83) & 315 & 1.091 & 0.296 \\
\hline Positive & $189(67.26)$ & $92(32.74)$ & 281 & & \\
\hline \multicolumn{6}{|l|}{ Nerve invasion } \\
\hline Negative & $343(66.22)$ & 175(33.78) & 518 & 2.168 & 0.141 \\
\hline Positive & $45(57.69)$ & $33(42.31)$ & 78 & & \\
\hline \multicolumn{6}{|l|}{ Vascular invasion } \\
\hline Negative & $359(64.80)$ & 195(35.20) & 554 & 0.310 & 0.578 \\
\hline Positive & $29(69.05)$ & 13(30.95) & 42 & & \\
\hline \multicolumn{6}{|l|}{ Differentiation } \\
\hline High & $206(64.58)$ & 113(35.42) & 319 & 2.778 & 0.249 \\
\hline Middle & $173(64.79)$ & $94(35.21)$ & 267 & & \\
\hline Low & $9(90.00)$ & $1(10.00)$ & 10 & & \\
\hline \multicolumn{6}{|l|}{ Tumor location } \\
\hline Up & $105(68.18)$ & $49(31.82)$ & 154 & 2.534 & 0.282 \\
\hline
\end{tabular}




\begin{tabular}{|llllll|} 
Middle & $179(63.03)$ & $105(36.97)$ & 284 & & \\
Down & $9(81.82)$ & $2(18.18)$ & 11 & & \\
\hline Invasion depth & & & & & \\
Mucous layer & $19(82.61)$ & $4(17.39)$ & 23 & 4.588 & 0.101 \\
\hline Muscle layer & $101(68.24)$ & $47(31.76)$ & 148 & & \\
Whole layer & $267(62.97)$ & $157(37.03)$ & 424 & & \\
\hline
\end{tabular}

\section{Figures}

A
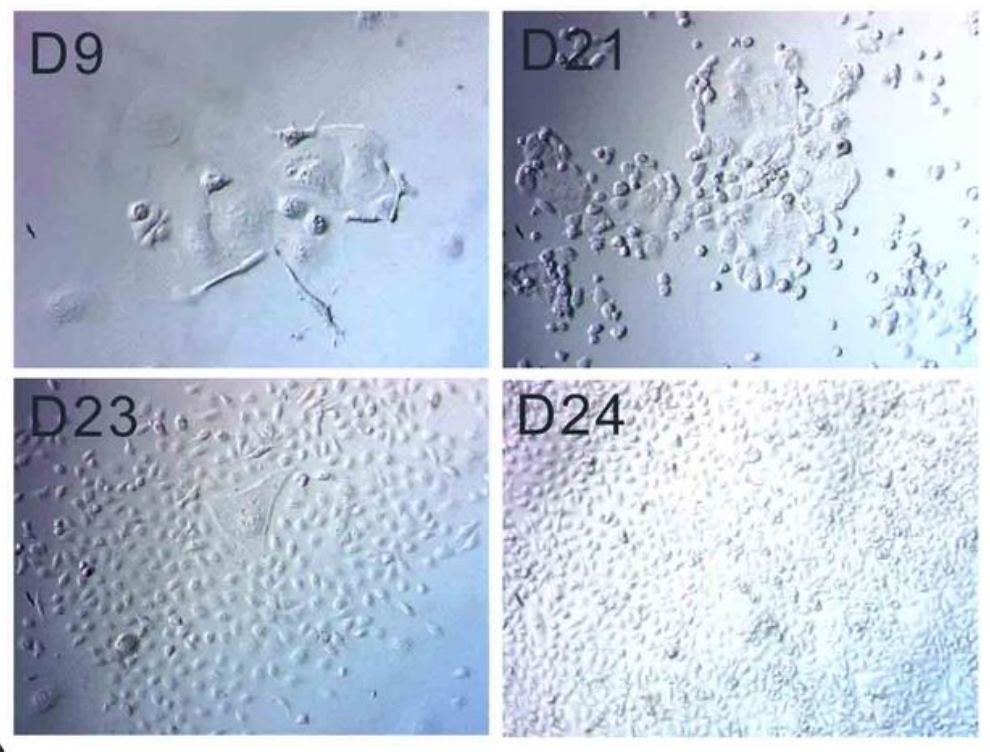

C

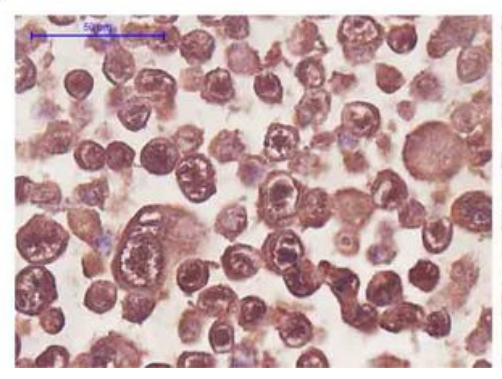

\section{B}

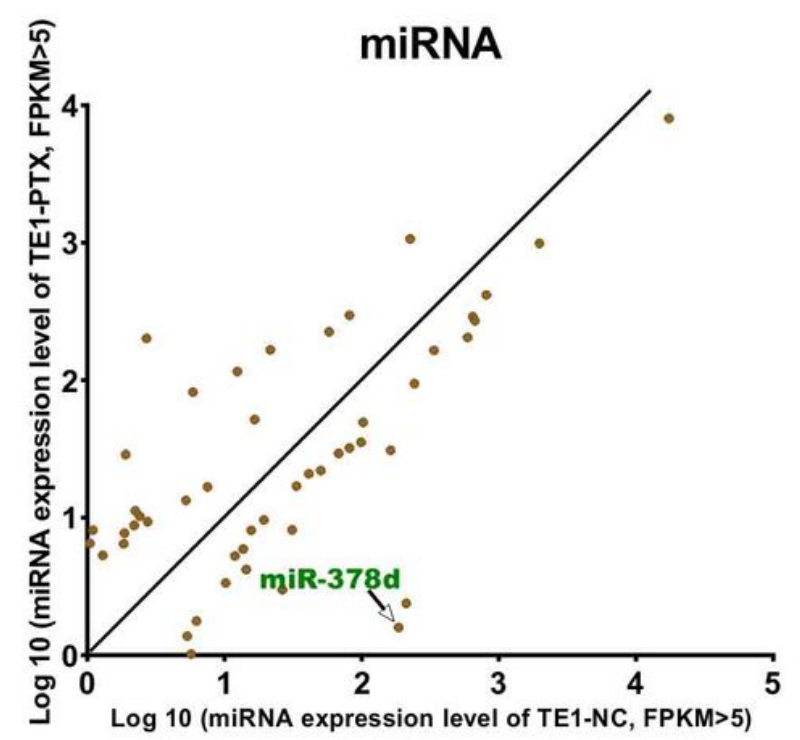

Figure 1

miR-378d was significantly reduced after PTX treatment. a Photographs of TE- 1 cells were taken at days $9,21,23$, and 24 after $350 \mathrm{nM}$ PTX treatment for $24 \mathrm{~h}$. b Scatterplot showing differential miRNA expression between TE-1-Ctrl and TE-1-PTX (day 9), fragments per kilobase million (FPKM)>5. c miR-378d expression was detected by in situ hybridization in TE-1 NC and TE-1-PTX. Scale bar: $50 \mu \mathrm{m}$. 
A

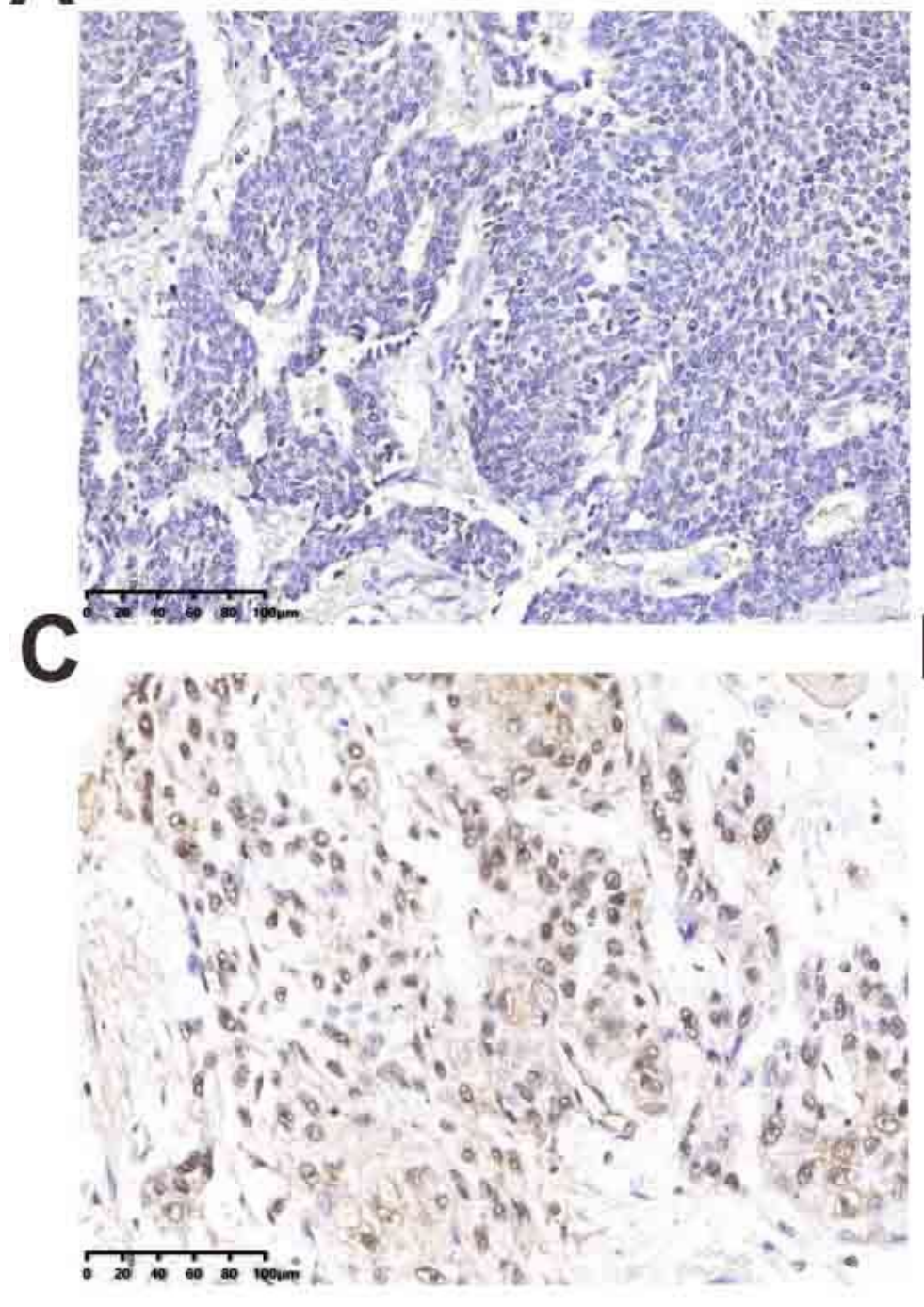

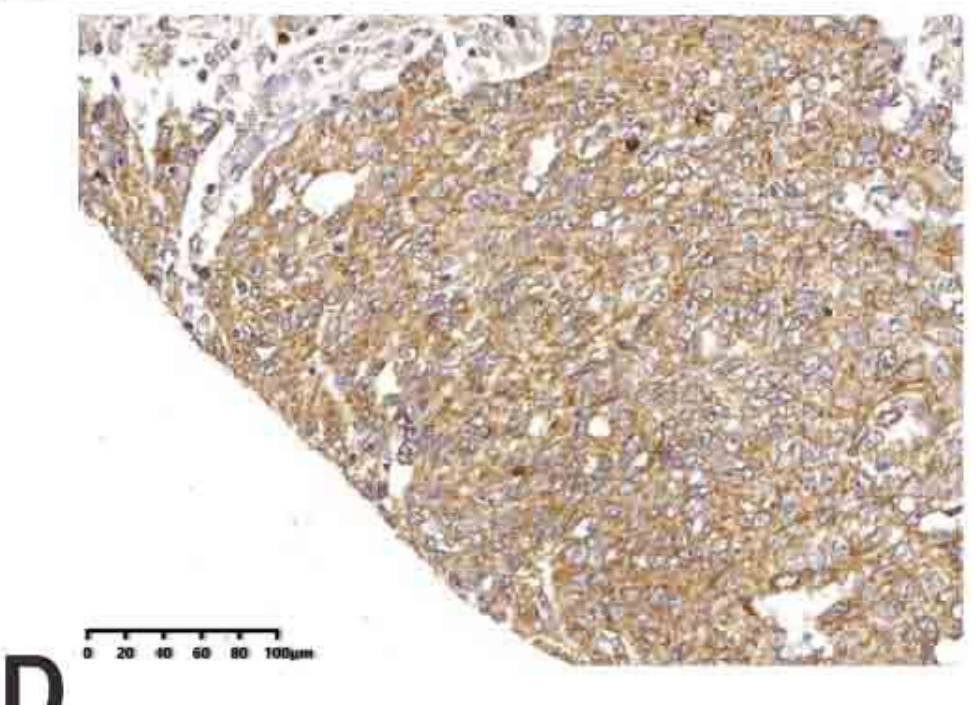

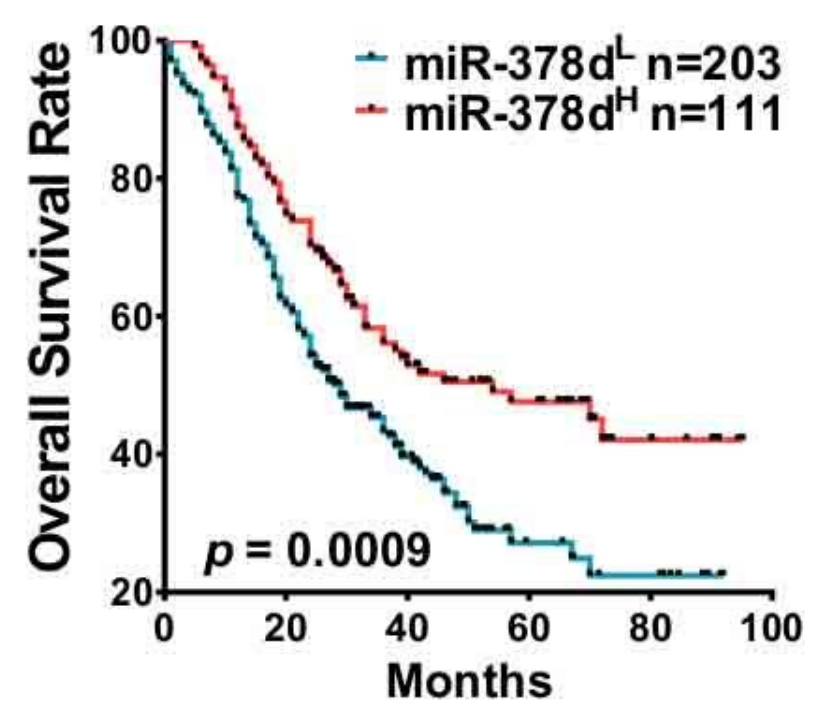

Figure 2

Patients with low miR-378d expression had poor prognosis. miR-378d expression was detected by in situ hybridization, a low expression, and b high expression in the cytoplasm and c nucleus of squamous cancer cells. d Overall survival rate of ESCC patients according to miR-378d expression levels. 
A TE-1
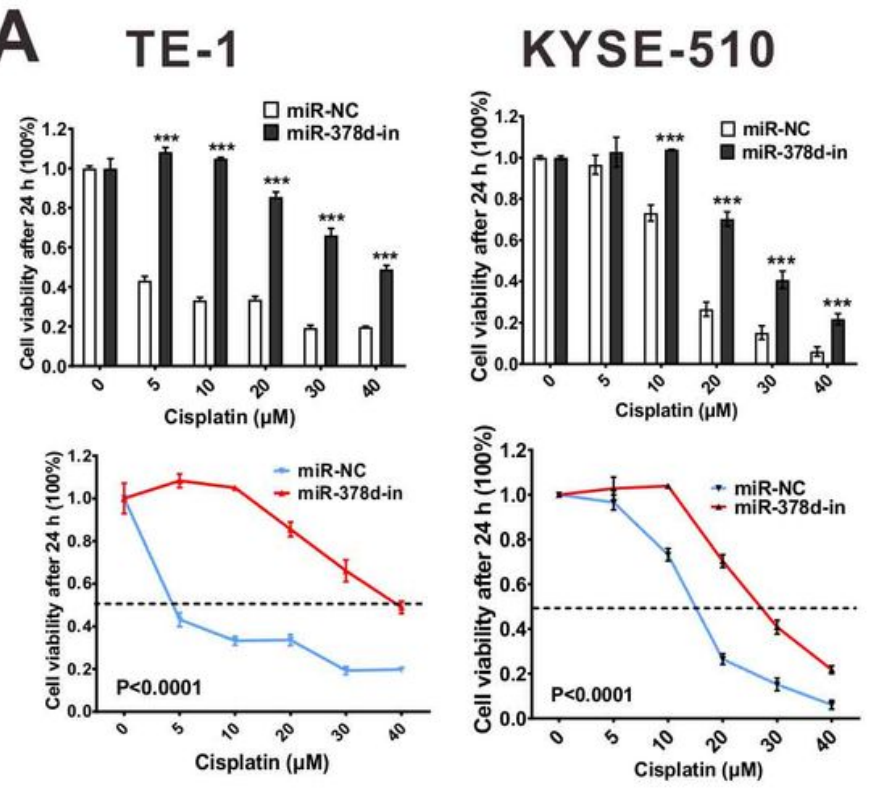

B
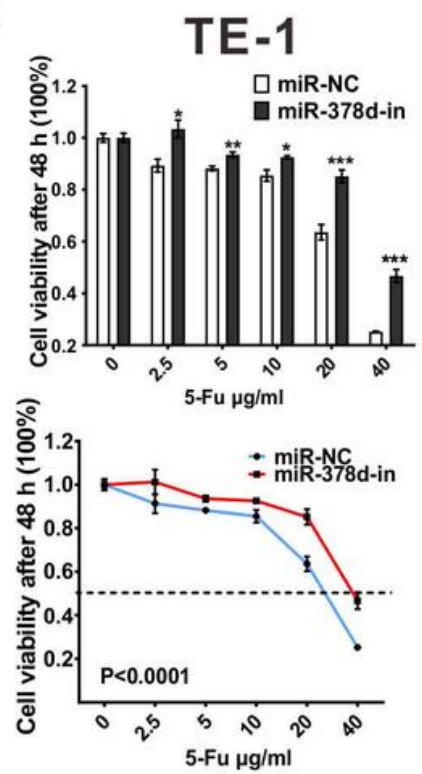

KYSE-510
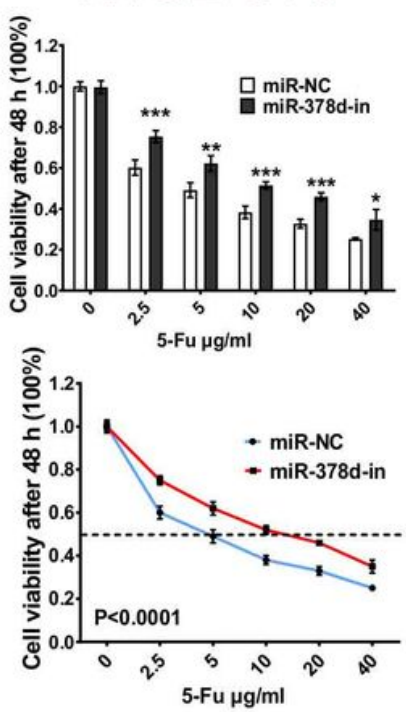

Figure 3

miR-378d absence promoted chemoresistance. a Silencing of miR-378d promoted the resistance of cisplatin of TE-1 and KYSE-510 cells. b Silencing of miR-378d promoted the resistance of 5-Fu of TE-1 and KYSE-510 cells. 


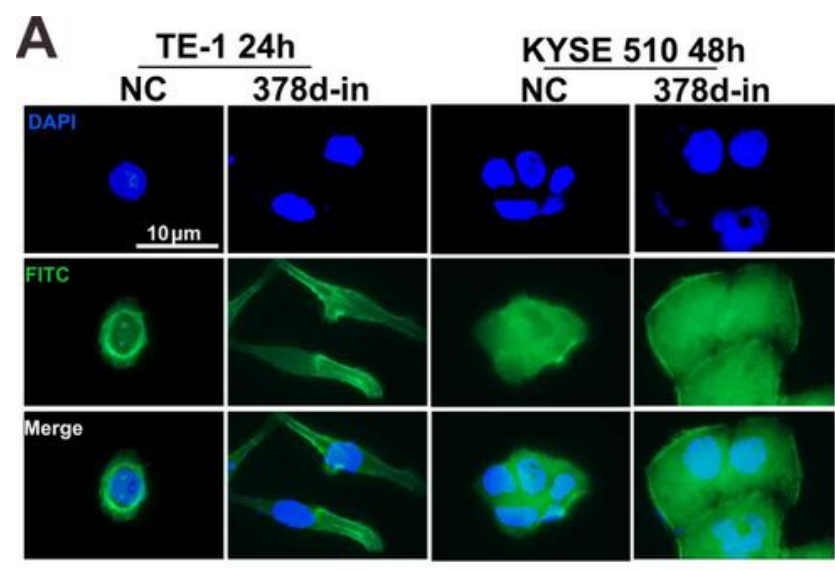

B
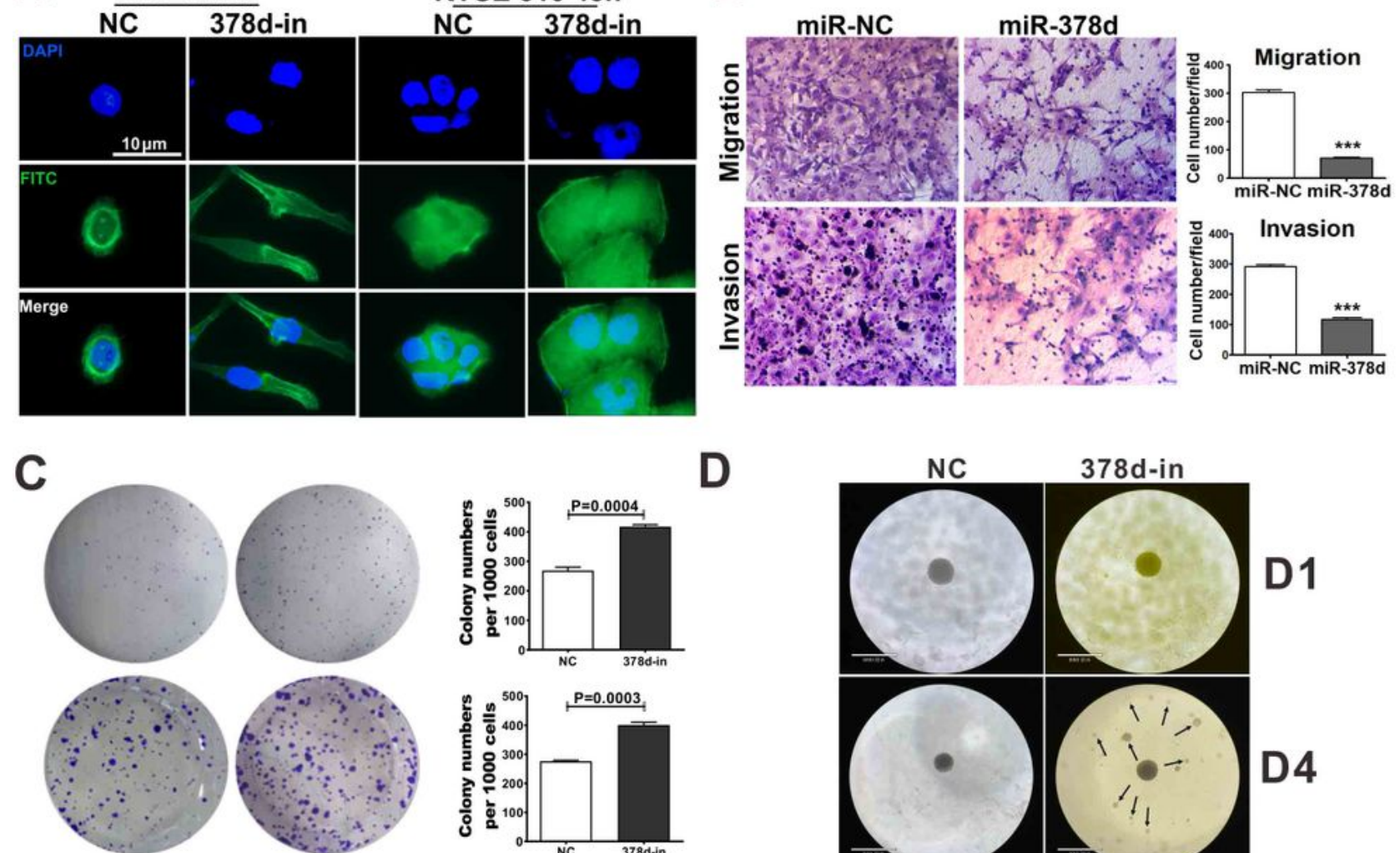

D
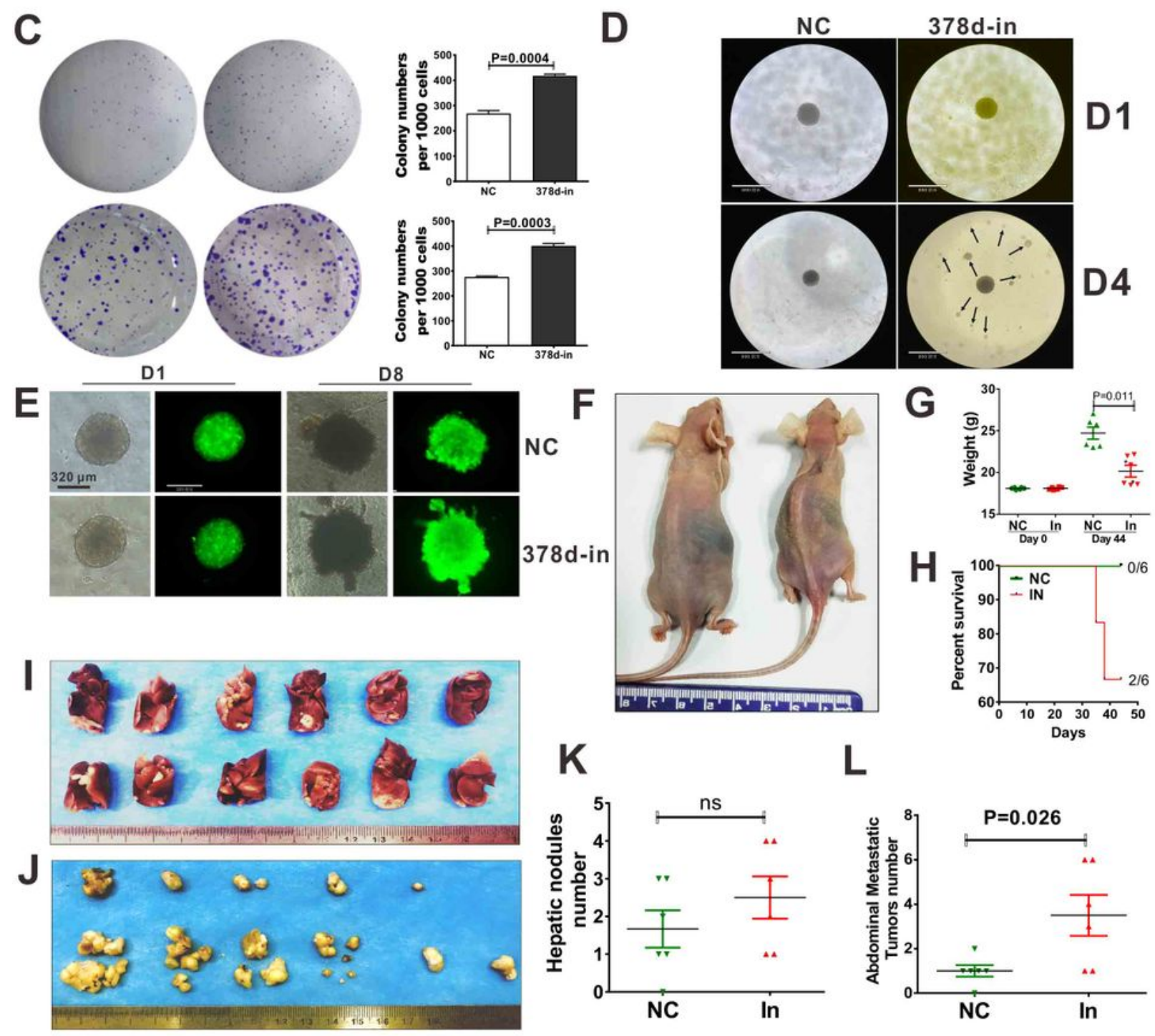

\section{Figure 4}

miR-378d absence promoted invasion and metastasis. a Phalloidin-FITC labeling the F-actin of TE-1miR-NC, TE-1-miR-378d-in, KYSE150-miR-NC, and KYSE150-miR-378d-in cells. b Transwell assay to detect the cell migration and invasion ability of TE-1-miR-NC and TE-1-miR-378d-mimic cells. c Silencing of miR378d promoted the monoclonal formation of TE-1 ( $P=0.0004)$ and KYSE510 $(P=0.0003)$ cells; each experiment was repeated three times. $d$ 3D tumor-sphere formation, suspension. e 3D tumor-sphere 
formation, in Matrigel. f Tumor-bearing mice with liver-transplantation tumors, 6six BALB/c nude mice in each group. g Mouse body weight at days 0 and 44, *: mouse died before day 44. Compared with NCmice, In-mice lost body weight. $\mathrm{h}$ Survival rate of mice. i Liver with transplantation tumors. j Abdominal metastatic tumors. $k$ Number of hepatic nodules, ns: no significance. L, Number of abdominal-metastasis tumors.

\section{A} Retrograde endocannabinoid
signaling

Regulation of actin cytoskeleton

Rap1 signaling pathway

Proteoglycans in cancer

Prostate cancer

PI3K-Akt signaling pathway

Non-small cell lung cancer

MicroRNAs in cancer

MAPK signaling pathway

Insulin secretion

Hypertrophic cardiomyopathy

( $\mathrm{HCM})$

Focal adhersion

ECM-receptor interaction

Dilated cardiomyopathy

Circadian entrainment

cGMP-PKG sinaling pathway

CAMP signaling pathway

Axon guidance

Arrhythmogenic right vebtricular cardiomyopathy(ARVC)

Adherens junction

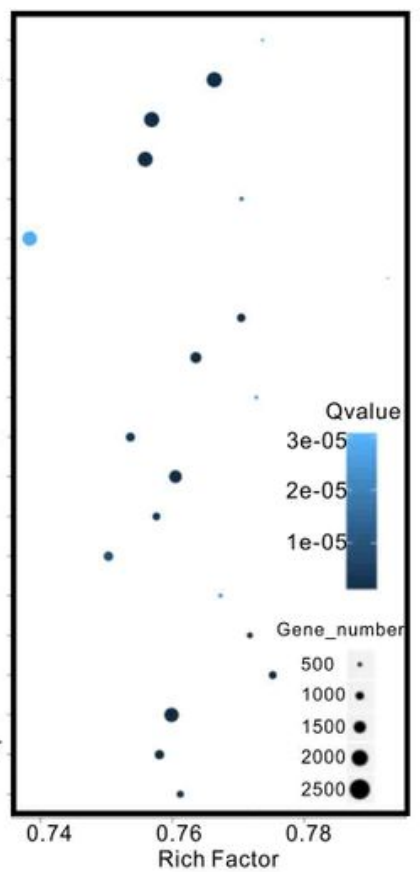

G

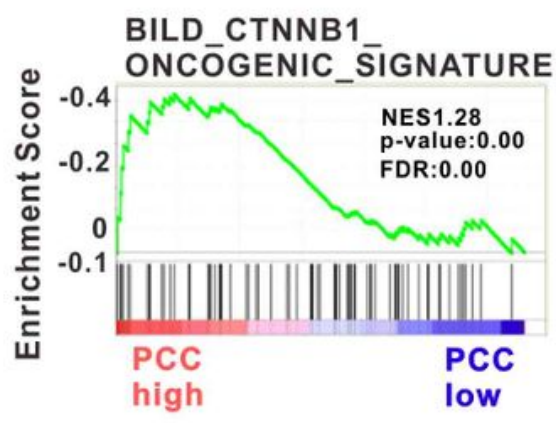

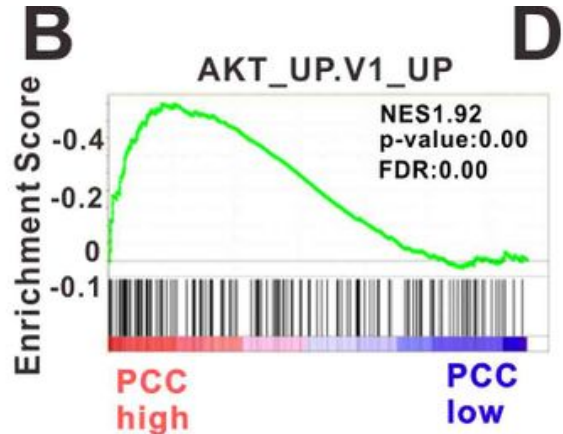

miR-378d 3' aaaGAC-UGAG-GUUCAGGUCa 5' WT 5' actCTGTCCTCTCGAGCCCAGa 3'

Mut 5' actGACTUGACTCGAGCCCAGa 3'

AKT1 3'UTR 109-130

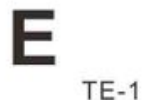

nc $378 d-m$
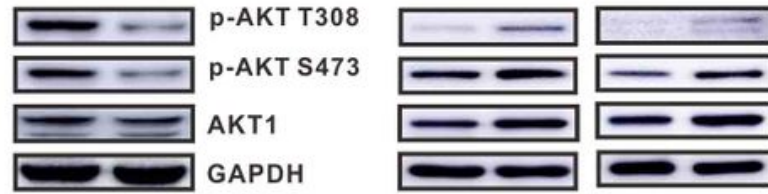

p-AKT T308

p-AKT S473

AKT1

GAPDH

$\mathrm{H}_{\mathrm{TE}-1}$

nc $378 d-m$
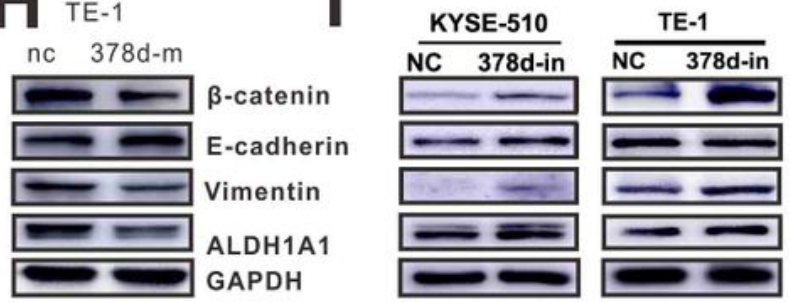

$\beta$-catenin

E-cadherin

Vimentin

ALDH1A1

GAPDH
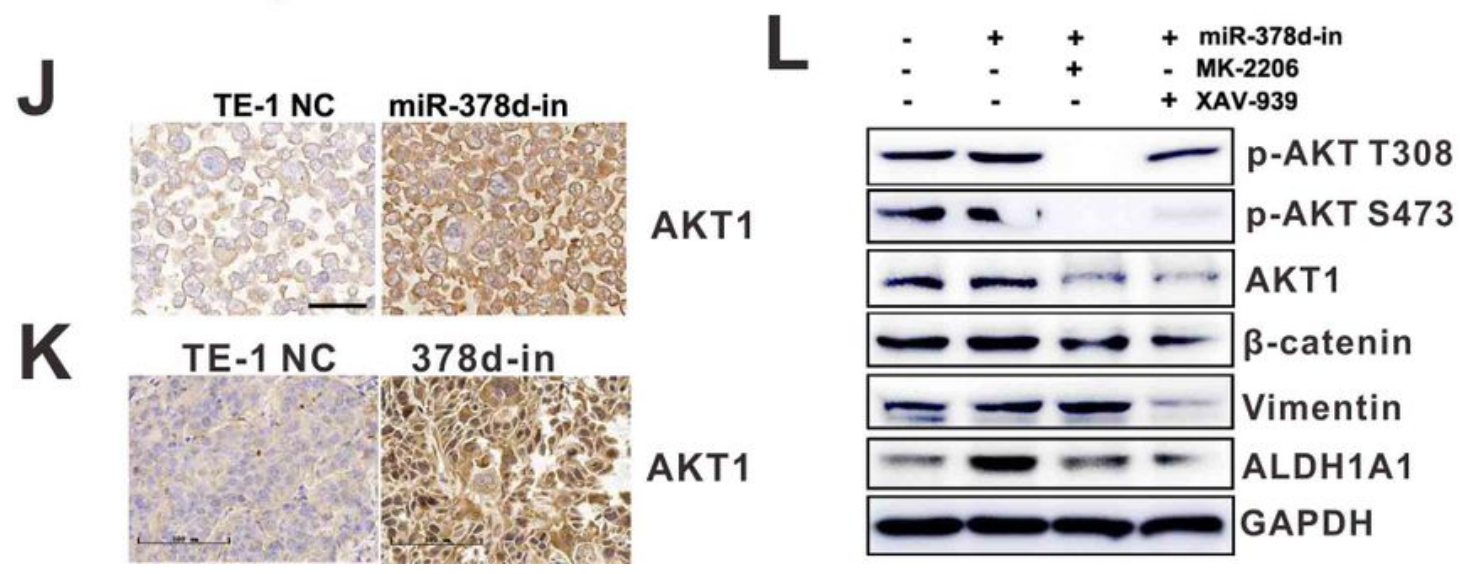

Figure 5 
miR-378d regulated AKT1 and AKT- $\beta$-catenin signaling. a Differentially expressed miRNA target geneenrichment analysis. b Gene-set enrichment analysis (GSEA) of TE-1 NC and TE-1 polyploid tumor cells for AKT. c Software prediction of binding sites between miR-378d and 3'UTR of AKT1 mRNA, and luciferase reporter vector designed containing wild type or mutation type of AKT1 mRNA 3'UTR (109-130 bp). d Du-luciferase activity assay; miR-378d reduced the luciferase activity of WT-AKT1-3'UTR but not that of Mut-AKT1-3'UTR. e Western blotting detected the protein expression levels of p-AKT and AKT; GAPDH served as an internal reference. $f$ Western blotting detected the protein expression levels of $p$-AKT and AKT; GAPDH served as an internal reference. $g$ Gene-set enrichment analysis (GSEA) of TE-1 NC and TE-1 polyploid tumor cells for CTNNB1 oncogenic signature. $h$ Western blotting assay detected the expression levels of $\beta$-catenin, E-cadherin, ALDH1A1, and Vimentin. GAPDH served as an internal reference. i Western blotting assay detected the expression levels of $\beta$-catenin, E-cadherin, ALDH1A1, and Vimentin. GAPDH served as an internal reference. j Immunocytochemistry for AKT1. Scale bar $=50 \mu \mathrm{m} . \mathrm{k}$ Immunohistochemistry for AKT1 in abdominal-metastasis tumors of NC and In-mice. Scale bar $=100 \mu \mathrm{m}$. I Western blotting detected the expression of p-AKT, AKT1, $\beta$-catenin, vimentin, ALDH1A1, and GAPDH after MK-2206 or XAV939 treatment. 

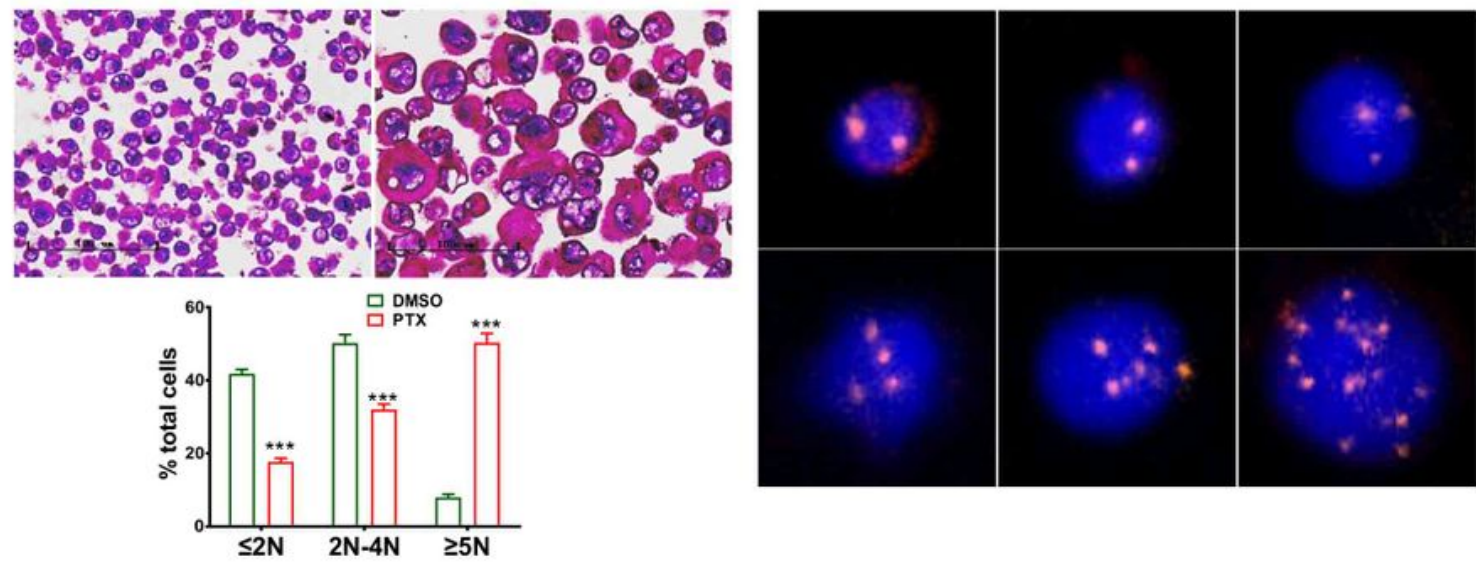
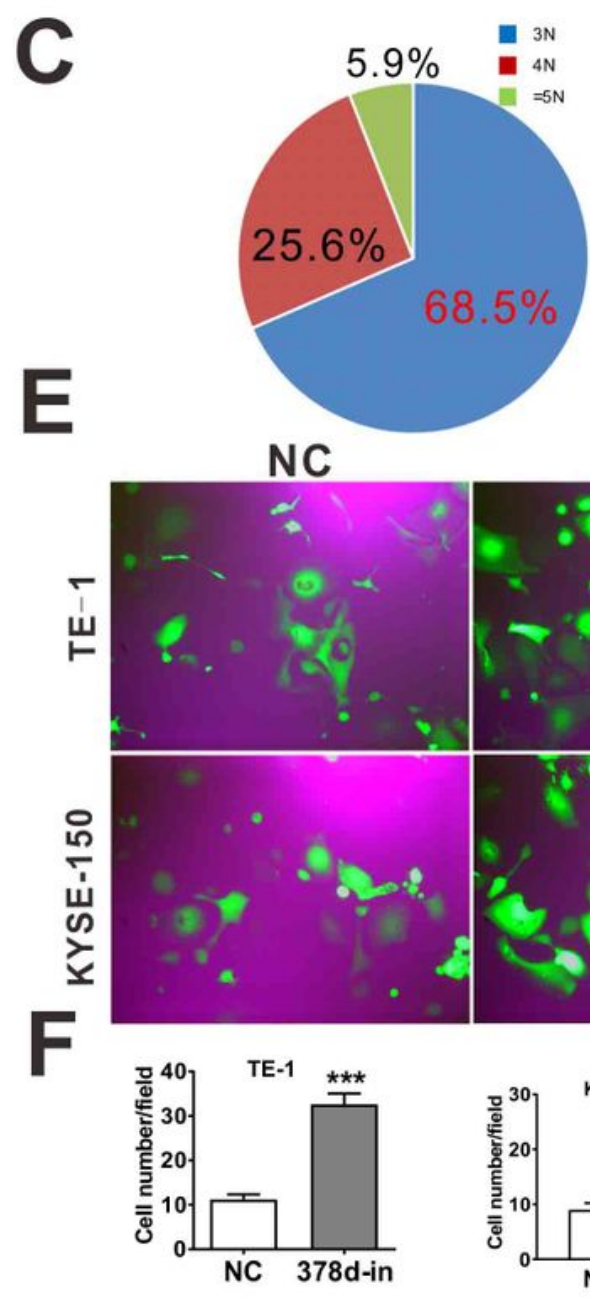
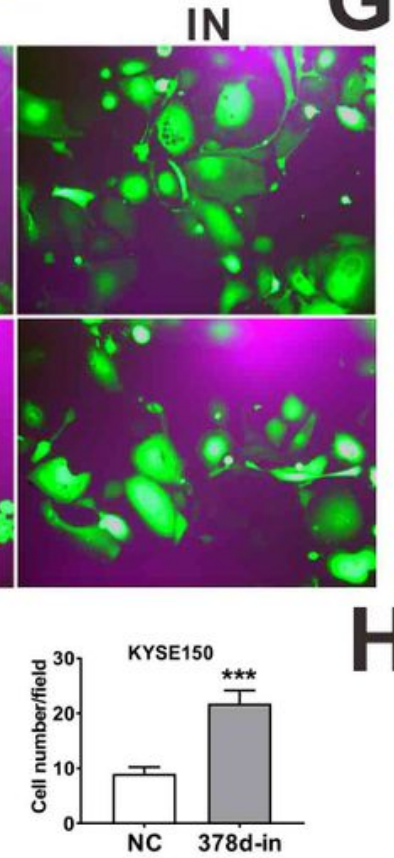

D
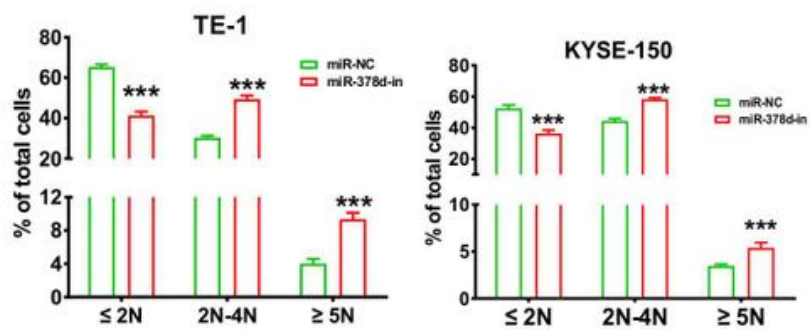

IN

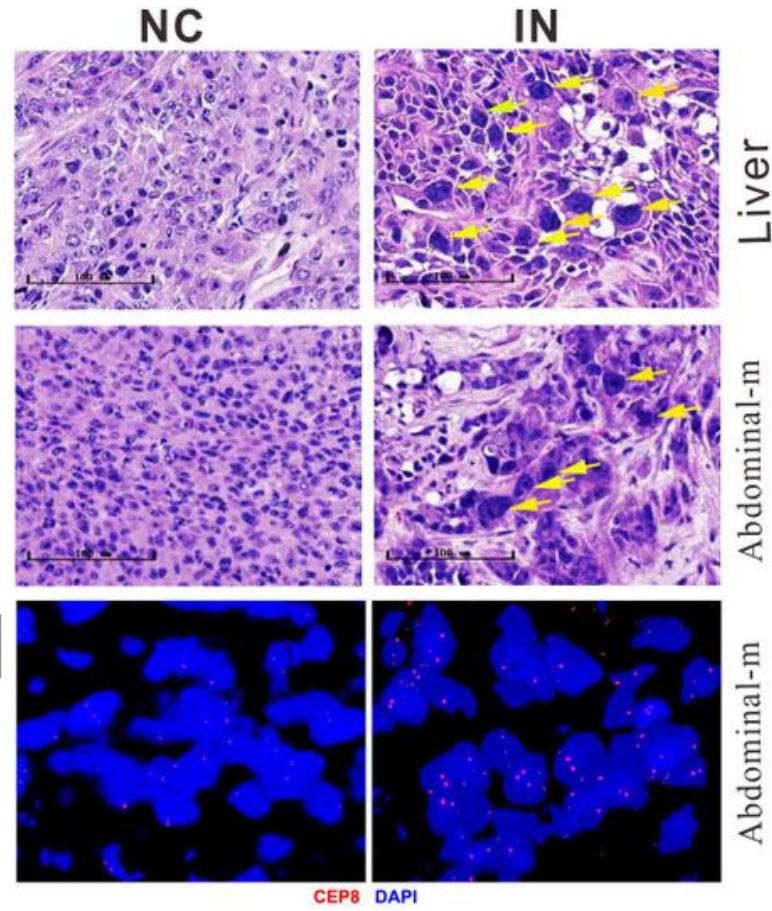

Figure 6

miR-378d inhibition promoted the formation of polyploid tumor cells. a HE staining for TE- 1 cells and TE1 polyploid tumor cells. Scale bar $=100 \mu \mathrm{m}$. b Different ploidy cells type of circulating tumor cells, 2N, 3N, $4 \mathrm{~N}$, and $\geq 5 \mathrm{~N}$. c Different CTC ratios of ESCC. D, miR-378d absence promoted the formation of $2 \mathrm{~N}-4 \mathrm{~N}$ and $\geq 5 \mathrm{~N}$ cells. e Polyploid tumor-cell formation at day 9 after PTX treatment, TE- 1 and KYSE-150 cells were infected by Lv-GFP-NC and Lv-GFP-miR-378d-inhibitor separately. Scale bar $=100 \mu \mathrm{m}$, randomly 
select five fields of vision, $* \star *: \mathrm{P}<0.001$. $\mathrm{f}$ DNA ploidy analysis of TE- 1 and KYSE-150 cells at day 9 after PTX treatment; assay was repeated three times, $\star \star \star: ~ P<0.001 . \mathrm{g} \mathrm{H} \& E$ staining, liver-transplantation tumors. Scale bar $=100 \mu \mathrm{m}$. H\&E staining, abdominal-metastasis tumors. Scale bar $=100 \mu \mathrm{m} . \mathrm{h}$ FISH detection of CEP8 for abdominal-metastasis tumors.

A
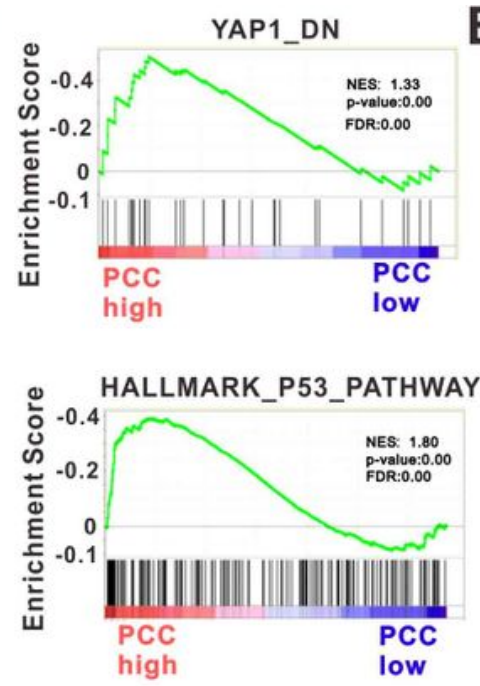$$
\text { C }
$$
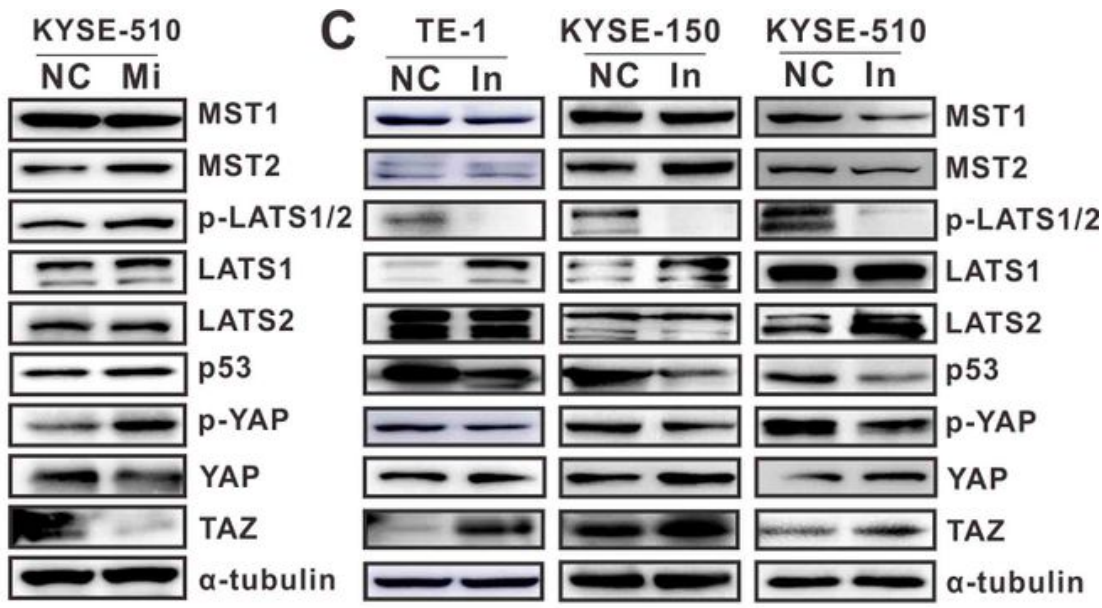

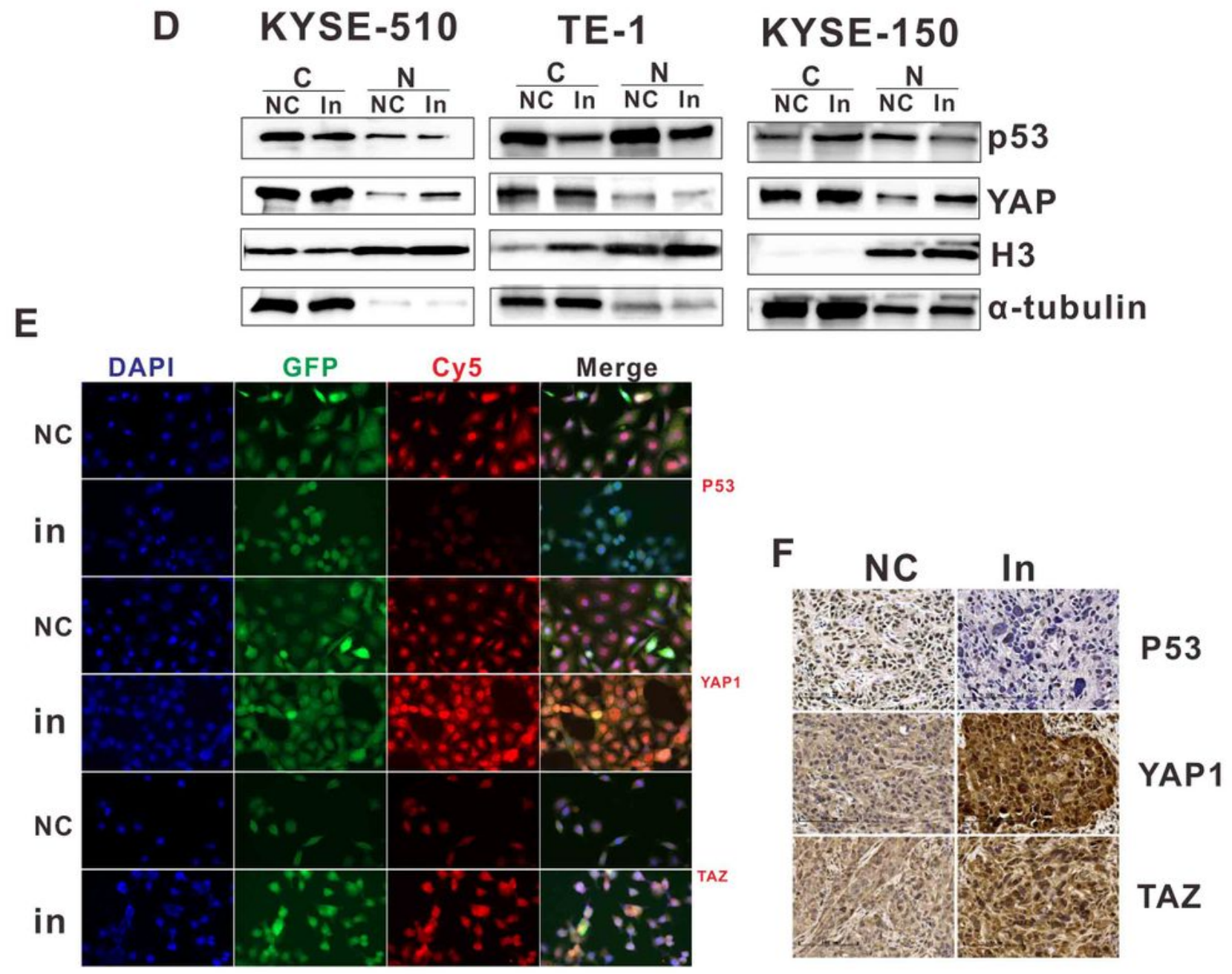

Figure 7 
miR-378d inhibition promoted the formation of PCCs by suppressing the Hippo-p53 signaling pathway. a Gene-set enrichment analysis (GSEA) of TE-1 NC and TE-1 PCCs for YAP1 and P53 pathway. b, c Western blotting to detect the protein expression levels of MST1, MST2, p-LATS1/2, LATS1, LATS2, p53, p-YAP, YAP, and TAZ. a-Tubulin served as an internal reference. $d$ Western blotting to detect the protein expression levels of P53 and YAP in the cytoplasm and nucleus. $\mathrm{H} 3$ and a-tubulin served as internal reference. e Immunofluorescence for TP53, YAP1, and TAZ. Scale bar = $20 \mu \mathrm{m}$. $\mathrm{fImmunohistochemistry}$ for TP53, YAP1, and TAZ. Scale bar $=100 \mu \mathrm{m}$. 